\title{
Relationships among the personal fable, drug use and parental monitoring in adolescents and young adults
}

Xin Liu

West Virginia University

Follow this and additional works at: https://researchrepository.wvu.edu/etd

\section{Recommended Citation}

Liu, Xin, "Relationships among the personal fable, drug use and parental monitoring in adolescents and young adults" (2011). Graduate Theses, Dissertations, and Problem Reports. 682.

https://researchrepository.wvu.edu/etd/682

This Thesis is protected by copyright and/or related rights. It has been brought to you by the The Research Repository @ WVU with permission from the rights-holder(s). You are free to use this Thesis in any way that is permitted by the copyright and related rights legislation that applies to your use. For other uses you must obtain permission from the rights-holder(s) directly, unless additional rights are indicated by a Creative Commons license in the record and/ or on the work itself. This Thesis has been accepted for inclusion in WVU Graduate Theses, Dissertations, and Problem Reports collection by an authorized administrator of The Research Repository @ WVU. For more information, please contact researchrepository@mail.wvu.edu. 


\title{
RELATIONSHIPS AMONG THE PERSONAL FABLE, DRUG USE AND PARENTAL MONITORING IN ADOLESCENTS AND YOUNG ADULTS
}

\section{Xin Liu}

Thesis submitted to the College of Human Resources and Education at West Virginia University in partial fulfillment of the requirements for the degree of

\author{
Master of the Arts \\ in \\ Educational Psychology \\ Kristin L. Moilanen, Ph.D., Chair \\ Carol A. Markstrom, Ph.D. \\ Aaron Metzger, Ph.D. \\ Department of Technology, Learning and Culture
}

\author{
Morgantown, West Virginia \\ 2011
}

Keywords: Personal Fable; Parental Monitoring; Youth Drug Use Copyright 2011 Xin Liu 


\title{
ABSTRACT \\ Relationships Among the Personal Fable, Drug Use and Parental Monitoring in Adolescents and Young Adults
}

\begin{abstract}
Xin Liu
Relationships among the personal fable, drug use and parental monitoring in adolescents and young adults were tested in this study. Participants were 56 students, with 25 from a small, suburban area in southern Michigan, and 32 from West Virginia University $(87.5 \%$ female, 94.6\% Caucasian). Participants completed questionnaires about demographics, the personal fable, parental monitoring and drug use in an online survey. Results showed that there was a negative correlation between parental monitoring and youth drug use, but no correlation between the personal fable and drug use. There was some evidence that the personal fable had a moderated effect on lifetime drug use via parental monitoring. Youth with parents that have more knowledge of their activities and whereabouts tended to be less likely to engage in lifetime and recent drug use, while youths' feelings of being invulnerable and special was not related to their drug use. Moreover, there is a hint that parents' knowledge can serve to moderate the effect of the personal fable in predicting youths' lifetime drug use.
\end{abstract}




\section{ACKNOWLEDGEMENTS}

I would like to express my sincerest thankful to all my committee members, their professional instructions and suggestions supported me to complete the thesis. Especially, I would like to thank my advisor Dr. Kristin Moilanen for guiding me and encouraging me in the whole process of my research design, data analysis and the thesis writing. Her great personality and patience make me feel warmth and supported. I also would like to offer my great appreciation to Dr. Carol Markstrom, for the thoughtful suggestion and the inspiration I got from her class, which helps to build my thesis. In addition, I would like to thank Dr. Aaron Metzger's suggestions that guided me to think more possibilities and to do my study precisely. Compared to all the suggestions and supports my committee members gave to me, my world here is so insufficient. Again, I would not be able to complete my thesis so smooth without all your support and help. Moreover, I would like to send my appreciation to my family for their love and support. I also appreciated my best friend and roommate ChengCheng Xiang, for her encouragement and all the help during my Master study. Moreover, I would like to thank Dr. Amy Root's support and Judy Martin and Melanie Hockenberry's encouragement and help. Last but not least, I would like to thank Dr. Suzanne Hartman, Stephanie Clarke and Katie Elizabeth Rasmussen's help during my data collection. 


\section{TABLE OF CONTENTS}

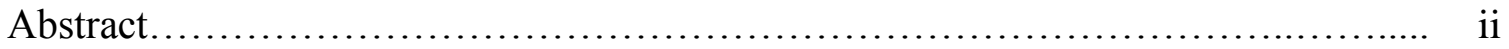

Acknowledgments...................................................... iii

Table of Contents...................................................... iv

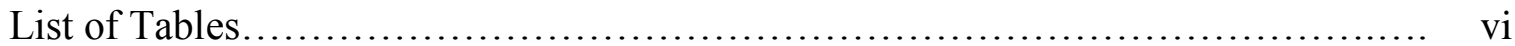

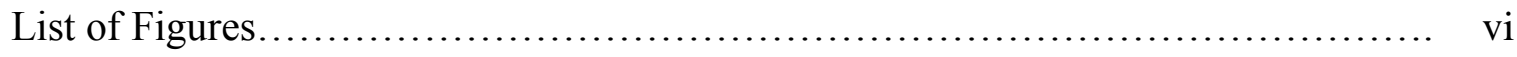

Chapter 1: Introduction................................................ 1

Overview ...................................................... 1

Problem Statement and Purpose................................ 3

Chapter 2: Theoretical Framework and Literature Review.................... 5

Theory Overview........................................ 5

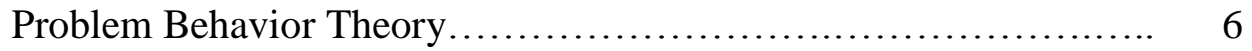

Egocentrism Theory...................................... 9

Parental monitoring/Knowledge Overview...................... 11

Parental monitoring and Drug Use............................ 12

Adolescence Egocentrism: Personal Fable and Drug Use............ 19

Parental monitoring as a moderator............................ 26

Hypotheses............................................ 28

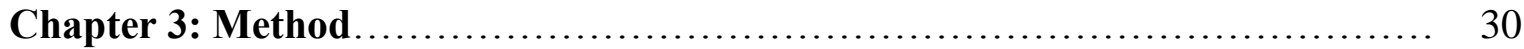

Participants.............................................. 30

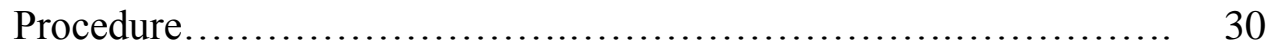

Measures........................................................ 31

Demographics.......................................... 31 


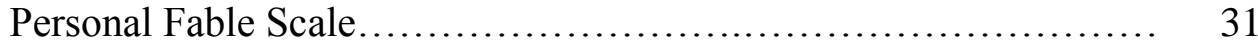

Parental Monitoring Scale..................................... 32

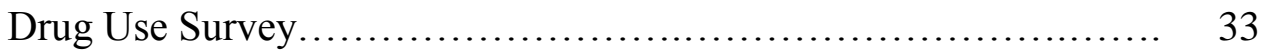

Analytic Strategy............................................... 34

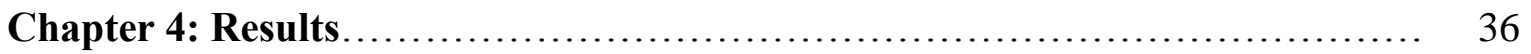

Correlation Analysis........................................... 36

Regression Analysis.......................................... 36

Lifetime Drug Use........................................... 37

Recent Drug Use.................................................. 38

ANOVA Analysis............................................ 38

Chapter 5: Discussion .......................................................... 40

Parental Monitoring ............................................... 40

Personal Fable ................................................. 42

Parental Monitoring as a Moderator................................... 44

Limitation and Future Directions................................ 47

Contributions................................................. 49

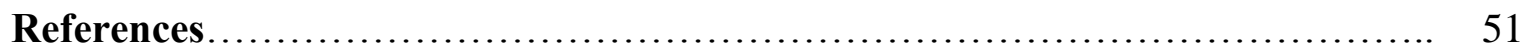

APPENDIX A: DEMOGRAPHIC INFORMATION ............................ 58

APPENDIX B: DEMOGRAPHIC INFORMATION (College)...................... 60

APPENDIX C: PERSONAL FABLE SCALE ................................. 62

APPENDIX D: PARENTAL MONITORING SCALE ........................... 63

APPENDIX E: SUBSTANCE USE................................................ 64 


\section{List of Tables}

Table 1-Study Variable Descriptive Statistics by subsample........................ 66

Table 2-Study Variable Descriptive Statistics \& Correlations....................... 68

Table 3-Results of Hierarchical Regression Analysis Predicting Youth Lifetime Drug

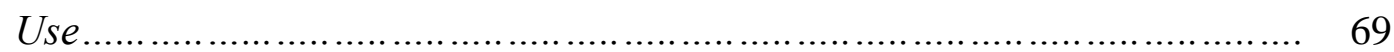

Table 4-Results of Hierarchical Regression Analysis Predicting Recent Drug Use..... 70

\section{List of Figures}

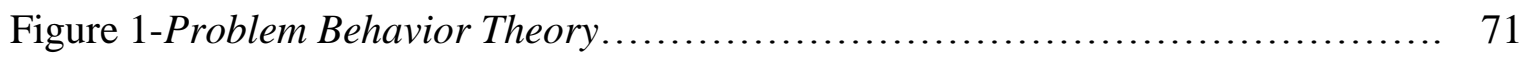

Figure 2- Interaction effect of parental monitoring and the personal fable on youths'

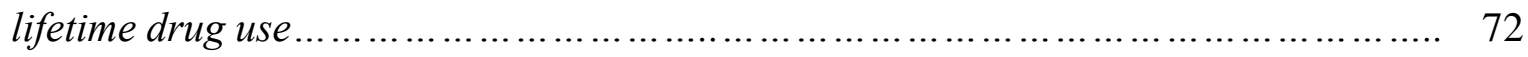




\section{Personal Fable, Drug Use and Parental Monitoring in Adolescents and Young Adults}

\section{CHAPTER 1 \\ INTRODUCTION}

\section{Overview}

Across all of human development, adolescence is one of the most important stages. This is the time when people try to find who they are, and in this stage, young people will face many changes and choices. During this special period, young people sometimes engage in behaviors that are high risk, including drug use, delinquency, alcohol, unsafe sex, etc. Among these risk behaviors, substance use is a serious problem which includes alcohol use, tobacco use, etc. The 2009 National Survey on Drug Use and Health (NSDUH) report mentioned that $10 \%$ of adolescents (ages 12 to 17 years) used illicit drugs in the past month (NSDUH, 2010). Specific data on tobacco use from the U.S. Centers for Disease Control (CDC) shows that, every day, there are about 3,600 youth who begin to engage in smoking behavior and each year, in every five deaths, there is one caused by tobacco use (CDC, 2010). The situation is even worse for alcohol use. Official data from the year of 2009 indicated that nearly $20 \%$ of high school age students engaged in drinking behavior (CDC, 2010). When drug use is combined with other risk behaviors, these tragedies will increase. For example, driving after using alcohol caused $40 \%$ of the deaths in vehicle accidents and drug/alcohol use relates to other risk behaviors such as delinquent behaviors (CDC, 2010). Likewise, the situation is not optimistic in other cultures as well. In a study of risk behaviors among Hong Kong's adolescents (ages 10 to 19 years), it was found that among 26,111 participants, $18 \%$ had the experience of smoking (Lee \& Tsang, 2004). The serious situation is similar in Australia (Bright, McKillop, \& Ryder, 2008).

Drug use behaviors are harmful to adolescents. For example, such behaviors can harm adolescents' health heavily through damaging the brain. A study by Brown et al. (2009) found 
Personal Fable, Drug Use and Parental Monitoring in Adolescents and Young Adults

that drug use was harmful for the central nervous system and the study completed by Yucel et al. (2010) found that long-term users had damage to the brain's white matter, which can lead adolescents to engage in risk behaviors such as delinquency and other aggressive behaviors. In addition, a fact sheet from the Office of National Drug Control Policy (ONDCP) indicated that marijuana, which is popular among youth drug users, is harmful to short-term memory (ONDCP, n.d.). Not limited to only physical harm, drug use has similarly been confirmed to influence youth academic achievement and other risk behaviors as well. Townsend, Flisher and King (2007) reviewed several previous literatures in their study and found that youth substance use (cigarette and marijuana) was significant positively related to high school students' dropping out and low academic achievement. Other research has confirmed that drug use can lead to youth engaging in other risk behaviors, such as the unsafe sexual intercourse, which might cause HIV (Elkington, Bauermeister, Brackis-Cott, Dolezal, \& Mellins, 2009). In addition, sometimes adolescents might choose to use drugs as an effective strategy to deal with their problems such as negative feelings or anxiety (McKenzie, Olsson, Jorm, Romaniuk, \& Patton, 2010).

More importantly, adolescence is a special stage when individuals form their adult lifestyles so risk behaviors and bad behavior patterns in adolescence might have long term impacts on their later lives (Newcomb \& Bentler, 1988). For example, drug use in adolescence can significantly relate to future drug problems, physical health and family problems (i.e., negative relationships with other members in the family) in adulthood (Newcomb \& Bentler, 1988). When youth drug users transformed to late adolescence, they are more likely to engage in other risk behaviors such as unsafe sexual intercourse, in addition, they will be more likely became serious users compared with those who begin to use later (ONDCP, n.d.). 
Personal Fable, Drug Use and Parental Monitoring in Adolescents and Young Adults

The serious situation of youth drug use and its harmful effects make it important to study this issue. Previous researchers did some work on youth drug use according to various aspects, such as in association with drug using peers (Bot, Engels, Knibbe, \& Meeus, 2005; Henry, Oetting, \& Slater, 2009), parental monitoring (Fulkerson, Pasch, Perry, \& Komro, 2008; Kristjanssonet, James, Allegrante, Sigfusdottir, \& Helgason, 2010; Li, Feigelman, \& Stanton, 2000), and personal fable (Alberts, Elkind, \& Ginsberg, 2007; Greene, Krcmar, Walters, Rubin, Jerold, \& Hale, 2000; Omori \& Ingersoll, 2005). However, there was no specific research focused on youth drug use considering both parental monitoring and personal fable. The study here will fill in this gap.

This study explored the issue of youth drug use based on previous work on the relationship between personal fable and drug use, and the association between parental monitoring and drug use. Moreover, this research is designed to seek further relationships among these three variables.

\section{Problem Statement and Purpose}

Since adolescents risk behavior is such an urgent problem in today's societies and all over the world, it is important to do research on this topic and try to find the solution. The current study was designed at investigating this problem in terms of two antecedents: the personal fable in the youth personality system and the parental monitoring in the social system. Personal fable refers to the youth's "feeling of specialty and invulnerability" (Elkind, 1967, p. 44). Parental monitoring refers to parents' knowledge of their children's whereabouts and activities (Kerr \& Stattin, 2000). These two variables are importantly associated with youth behaviors (Elkind, 1967; Kerr \& Stattin, 2000).

This topic is important because although much is known about how parental monitoring is 
Personal Fable, Drug Use and Parental Monitoring in Adolescents and Young Adults

associated with substance use in adolescence (Beck, Boyle, \& Boekeloo, 2003; DiClemente et al., 2001), there are limited studies about the associations between the personal fable and adolescent substance use; and these studies have contradicting results (Aalsma, Lapsley, \& Flannery, 2006; Bright et al., 2008; Omori \& Ingersoll, 2005). The current study was designed to explore the relationships among the personal fable, youth drug use and parental monitoring. As part of this investigation, the question of whether parental monitoring can serve as a moderator and influence the association between personal fable and drug use will also be studied. Specifically, the study was designed to explore whether parental monitoring can serve as a moderating protective factor to reduce children's drug use even if they have high levels of the personal fable. Furthermore, the result of the current study might be able to provide some suggestions for families and the society for the prevention of drug use in adolescence. If the study can target the reason why adolescents engage in risk behavior and find that parental monitoring can help to prevent it, then this study may have applicable value for helping prevent or reduce youth drug use by emphasize parents' monitoring. Both family and society can help to reduce youth drug use and maybe other kinds of risk behaviors. 
Personal Fable, Drug Use and Parental Monitoring in Adolescents and Young Adults

\section{CHAPTER 2}

\section{THEORETICAL FRAMEWORK AND LITERATURE REVIEW}

\section{Theory Overview}

The focus of the current study is the contribution of both internal and external risk factors to adolescents' drug use. There are two theories used in this study, one is problem behavior theory and the other is adolescence egocentrism theory. Problem behavior theory is the main theory guiding this study (Costa, 2008; Jessor \& Jessor, 1977; Jessor, 1991). According to Jessor and Jessor (1977) and Costa (2008), problem behaviors come from different systems. The two that are relevant for the current study are the perceived environment system and personality system, which respectively explain youth's drug use from the external or environment level and the internal or individual level.

The personality system or internal risk factor represented in the current study is the personal fable, which comes from the egocentrism theory created by David Elkind (1967). In adolescence egocentrism theory, the personal fable is "the feeling of specialty and invulnerability" (Elkind, 1967, p. 44). This means adolescents in this stage typically feel that they are special, and that they are powerful and can escape from danger, which may consequently increase their risk behaviors. People who report high levels of the personal fable also report high levels of risktaking behaviors, including substance use and unsafe sexual intercourse (Albert et al., 2007; Greene et al., 2000; Harris, Duncan, \& Boisjoly, 2002; Serovich \& Greene, 1997).

The perceived environment system or external risk factor selected for the current study is parental monitoring. Parental monitoring may be broadly defined as parents tracking their children and having knowledge of their children's whereabouts and activities (Stattin \& Kerr, 2000). Parents can get knowledge of their children's whereabouts and activities through three resources: child self-disclosure, parental solicitation and parental control (Stattin \& Kerr, 2000). 
Personal Fable, Drug Use and Parental Monitoring in Adolescents and Young Adults

Based on previous research, it can be hypothesized that high levels of parental monitoring were related to low levels of adolescents substance use (Beck, Boyle \& Boekeloo, 2003; DiClemente et al., 2001).

\section{Problem Behavior Theory}

Problem Behavior Theory (Jessor \& Jessor, 1968; Jessor, 1991) is a comprehensive psychosocial framework that can be used to explain why many adolescents tend to engage in some level of risk behaviors such as drug use. This theory is the one of the two theories that forms the basis of the current study.

Jessor and Jessor (1977) conceptualized problem behaviors as behaviors that are not valued by the society and are seen as deviant from normal behaviors. These risk behaviors are not valued because they are harmful for the individual, the family and the society. For example, the use of drugs can alter the structure and/or functioning of the brain, which may also cause common adolescent mental and behavioral problems (e.g., Yucel et al., 2010). Substance use leads to a high death rate in the general population ( $20 \%$ of yearly deaths each year are due to tobacco use and $40 \%$ of annual deaths are the result of alcohol-related motor accidents), and this makes families lose loved ones, change relationship structures and suffer pain (CDC, 2010). Also, drug use in adolescence can significantly relate to family problems which means youth might have negative relationships with their family members and this may have a long term impact on their other relationships when they transition to young adulthood (Newcomb \& Bentler, 1988). For society, drug use and other risk behaviors may not only cause society to lose high quality laborers, but also cause financial issues in that the money used to build intervention programs could instead be used to help other problems such as poverty. Youth smoking behavior in Australia can serve as an example for the financial cost of drug use: teenagers' 
Personal Fable, Drug Use and Parental Monitoring in Adolescents and Young Adults

smoking behavior costs $\$ 21$ billion in local money to build intervention programs (Bright et al., 2008). Moreover, drug use can also cause serious social problems: each year, around 100,000 adolescents were arrested because of substance abuse violations in the United States (Loftin, 2009).

In their theory, Jessor and Jessor stated that risk behaviors result from the interaction between the person and the environment (see Figure 1 for a depiction of this model) (Jessor \& Jessor, 1977; Jessor, 1991). There are five systems in the theory, representing both the individual and their environmental context: (a) biology/genetics (demography-social structure), (b) social environment, (c) perceived environment, (d) personality and (e) behavior. All five are independent systems, but they also relate to one another. Also, there are a large number of variables in each system that may increase or decrease the possibility of risk behavior; some are proximal and have direct effects on risk behaviors, while others are distal and have indirect links to problem behaviors (Costa, 2008; Jessor \& Jessor, 1977). Finally, individual variables within each system may work to promote or to increase the likelihood of risk behavior (i.e., risk factors), or to prevent or to decrease the likelihood of risk behavior (i.e., protective factors) (Costa, 2008; Jessor \& Jessor, 1977). In the current study, I will seek to explain adolescent drug use using variables from the personality system and the perceived environmental system of this theory. The personal fable will represent the personality system and parental monitoring will represent the perceived-environmental system.

In the personality system, the variables include individual values, personal beliefs, expectations and attitudes, and also beliefs or feelings toward other people or themselves. All of the variables are from a social cognitive foundation (e.g., reflecting how people see and recognize others and the world) and these can be categorized into three dimensions based on 
Personal Fable, Drug Use and Parental Monitoring in Adolescents and Young Adults

their effects (Costa, 2008; Jessor \& Jessor, 1977). The dimensions are the motivationalinstigation structure (e.g. values, expectations of academic achievement, independence, affection, etc.), the personal belief structure (e.g. social criticism, alienation, self-esteem) and the personal control structure (e.g. tolerant attitudes toward deviance)(Costa, 2008; Jessor \& Jessor, 1977). The current study uses the personal fable to look at youths' risk behaviors in relation to individuals' personality traits and it fits in the dimension of personal belief structure.

In perceived-environmental system, constructs include social control, parents and friends' support, and behavior models, etc. (Costa, 2008; Jessor \& Jessor, 1977). Variables in this system, such as models of peer behaviors and support from parents and others, are categorized into two structures: (a) the distal structure (e.g., parents or friends support and controls) and (b) the proximal structure (e.g., parents' or friends' approval or modeling of problem behaviors). Proximal variables influence behaviors directly and distal variables influence behaviors indirectly via other more proximal constructs (Costa, 2008; Jessor \& Jessor, 1977). The current study uses parental monitoring (a distal structure) to look at youth risk behavior from the perceived-environment level.

Variables in the risk behavior system include both problem/risk behaviors (e.g. drug use, problematic alcohol use, risky sexual intercourse) and normal conventional behaviors (e.g. going to church, academic performance (Costa, 2008; Jessor \& Jessor, 1977). In this study, the risk behavior system is represented via the outcome variable, which is drug use.

Although not a focus of the current investigation, biology/genetics (demography-social structure) and the social environment are the other systems of problem behavior theory. Variables in biology/genetics system are education level of fathers and mothers, the occupation of the parents, parents' religion beliefs and family structures (Jessor \& Jessor, 1977). Variables 
Personal Fable, Drug Use and Parental Monitoring in Adolescents and Young Adults

in the social environment are parental ideology (e.g. parental traditional beliefs), the influence of peers (e.g., interests of friends), media (e.g., television) and the climate in home (e.g., maternal controls-regulations) (Jessor \& Jessor, 1977). These types of social-environmental influences will not be included in the current investigation.

\section{Egocentrism Theory}

Elkind's adolescent egocentrism theory is based on Piaget's theory of cognitive development. According to Piaget (1970), when adolescents are in the formal operational stage, they begin to have abstract thoughts and are able to take other people's points of view, but their thinking is still characterized by egocentrism. Based on Piaget's work, Elkind (1967) elaborated on this concept of adolescent egocentrism, claiming that youth are not fully capable of distinguishing their thoughts about subject and object (Elkind, 1967). Elkind (1967) further differentiated two factors of adolescent egocentrism: one factor is called the imaginary audience and the other factor is the personal fable.

The imaginary audience means that people believe they are standing in the center of other people's observations, and that their behaviors and appearance are the focus of other people's judgments (Elkind, 1967). In other words, other people are concerned about their behaviors and appearance just as much as they themselves are concerned. They think that others are always focused on them and are judging their appearance or behaviors (Vartanian, 2000). Elkind and Bowen's (1979) study indicated that youth with high imaginary audience levels were more concerned other people's views about themselves. For example, when they asked adolescents to answer what they would feel or how they would act if they had a bad haircut, people with high levels of the imaginary audience believed that others would staring at them all the time and they didn't want to go out (Elkind \& Bowen, 1979). 
Personal Fable, Drug Use and Parental Monitoring in Adolescents and Young Adults

The other part of adolescent egocentrism is the personal fable. According to Elkind, the personal fable emerged during early adolescence and is "the feeling of specialty and invulnerability" (Elkind, 1967, p. 44). The personal fable includes feelings of invulnerability, personal uniqueness and omnipotence. Invulnerability refers to the feeling one cannot be damaged. Personal uniqueness refers to the feeling that the individual feels he or she is special or different from others. Omnipotence refers to the feeling that the individual has power and authority. Elkind (1967) indicated that though the personal fable can exist through human development, it reaches its highest level in adolescence. In one of Elkind's research studies with his colleagues in 2007, students in the $8^{\text {th }}$ grade had the highest level of the personal fable, compared to students in the 6th and 7th grades (Albertset al., 2007). When adolescents showed high levels of the personal fable (i.e., they viewed themselves as strong and immortal, and that bad things may only happen to others), they were more likely engage in risk behaviors (Alberts et al., 2007; Elkind, 1967). However, studies reviewed in Vartanian's (2000) paper challenged the view that personal fable is related to cognitive development and is higher in early adolescence. Vartanian mentioned in her study that many previous research did not find the significant positive relationship between cognitive stages and personal fable, in addition, she pointed out that the results of age difference was inconsistent (Vartanian, 2000). Science some of the researchers cannot confirm the personal fable was based on cognitive theory, other researchers tries to explain personal fable's emerging from other basis (Vartanian, 2000).

There was another explanation about the personal fable proposed by Lapsley (1993) using social cognitive development bases. Lapsley (1993) proposed that it is the young adolescent have difficulty viewing themselves' thoughts from a third person perspective, also, they have difficulty viewing other's perspectives from a third person viewpoint, and these accounted for 
Personal Fable, Drug Use and Parental Monitoring in Adolescents and Young Adults

the personal fable. Although the reason of why adolescents have the personal fable is an issue of debate, the phenomenon of the personal fable exists is not controversial. According to previous study, the dimension of invulnerability and specialty were significant associated with youth risk taking (Alberts et al., 2007). Therefore, the current study focused on these two dimensions in personal fable to explore the relationship among personal fable, parental monitoring, and youth drug use.

Overall, the Problem Behavior theory and Adolescence Egocentrism theory provided the theory background to explain youth risk behavior. Both youth personal fable in the personality level and the parental monitoring in the perceived-environment level were used to explore youth risk behaviors in the current study. Previous studies focused on youth personal fable, parental monitoring and drug use were reviewed in the following section.

\section{Parental Knowledge/Monitoring Overview}

Parental monitoring has no official definition, according to Kerr and Stattin (2000), it refers to parents' knowledge of their children's whereabouts and daily activities and comes from tracking and surveillance. In Dishion and McMahon's (1998) study, they defined it as parents' behaviors involving tracking and attention to the child's whereabouts and activities. Frequently, researchers equate parental monitoring with parental knowledge. Kerr and Stattin (2000) provided a further in-depth view about parental monitoring and they indicated that parents are tracking and getting knowledge about their children through three pathways which are child selfdisclosure, parental solicitation and parental control. Child disclosure means that children will initiate talking to their parents about what they are doing, who they are hanging out with, etc. Parental solicitation means that parents collect information about children through discussions with them or with the people around them. Parental control means parents control their 
Personal Fable, Drug Use and Parental Monitoring in Adolescents and Young Adults

children's activities, and when children need to do something, they must obtain permission first. In keeping with other recent investigations on parental monitoring, in the current study, parental monitoring is simply defined as the level of parental knowledge about their children's activities (Moilanen, Shaw, Criss, \& Dishion, 2009). It is parents' knowledge in general, but not the resources of how parents get their knowledge that was the focus of the current study. Relevant research on adolescent drug use and parental monitoring, particularly parental knowledge, is reviewed below.

\section{Parental Monitoring and Substance Use}

For the relationship between parental monitoring and substance use, previous works that diverse in research methods and sample characteristics were reviewed.

Shillington, Lehman, Clapp, Hovell, Sopan and Blumberg (2005). In Shillington and colleagues' (2005) research on parental monitoring and adolescent risk behavior, they focused on high-risk youths' drug and alcohol use. They hypothesized that high levels of parental monitoring were associated with low levels of substance use. In their study, the participants were 187 high-risk youth (ages 14 to 24 and the average age is 17.3) in southern California. The sample was comprised largely of at-risk youth, including gay, lesbian, bisexual and questioning adolescents as well as runaway and homeless youth and was approximately $42 \%$ Hispanic, $30 \%$ European American, 11\% African American). Among these participants, 112 were male and 75 were female. Data collected in this study included substance use (lifetime and the past 3 months), parental monitoring, demographic variables and ecological variables. Parental monitoring was assessed by asking participants if their parents or guardians had the knowledge of who they are hanging out with, where they are, and what they are doing. Substance use included the participants' report of their lifetime and past three months use of cigarettes, alcohol, 
Personal Fable, Drug Use and Parental Monitoring in Adolescents and Young Adults

marijuana, methamphetamine, ecstasy, and inhalants.

After data collection, researchers used chi-squares and logistic regression models to analyze the data and they found that after controlling for covariates, such as gender, high levels of parental monitoring were associated with low levels of alcohol and drug use. The participants who had no or low parental monitoring showed more engagement in alcohol use in the past 3 month period and in lifetime drug use. This study showed that when parents of these at-risk adolescents had higher levels of monitoring and had the knowledge of where they were going and who they were hanging out with, it was less likely that these youth engaged in alcohol and drug use. It can be concluded from this study that when parents or caregivers have more knowledge of children's activities, their children were less likely engage in alcohol/drug use in the past three months.

Beck et al. (2003). Beck and colleagues (2003) developed a study to assess the relationship between youth alcohol use and parental monitoring in a clinical population. The hypothesis for this study was that adolescents who reported high levels of parental monitoring would show less involvement in drinking behaviors. The participants in this study were 444 adolescents $(44.8 \%$ male, $55.2 \%$ female) whose ages ranged from 12 to 17 years and most of them were African American (79.3\%) from a medical based alcohol intervention program. The measure used to collect data on parental monitoring was modified from a scale used by Stanton et al. (2000) which has been used to assess parental monitoring of African American adolescents who live in inner-city settings. Risky alcohol use behavior was assessed by ask participants if they used alcohol in the past year, past three month or last 30 days, or have get alcohol from stores. After data collection, researchers used logistic regressions to analyze the data and controlling for age and gender in the analysis. Results showed that adolescents who reported high levels of parental 
Personal Fable, Drug Use and Parental Monitoring in Adolescents and Young Adults

monitoring were less likely to be involved in drinking behavior or to be in environments that might be harmful, such as the places where peers drink alcohol. All of these findings showed that parental monitoring can act as an important factor to protect adolescents from risky alcohol use behaviors. This study shows that parental monitoring can serve as a protective factor to retard youth alcohol use.

Webb, Bray, Getz, and Adams (2002). Webb et al. (2002) designed a longitudinal study to look at relationships among gender, parental monitoring and youth alcohol use. The hypothesis for this study was that parental monitoring would relate to youth alcohol use and females especially would receive more monitoring by their mothers. Participants in this study were 1126 students (49\% male and $51 \%$ female) in $7^{\text {th }}$ through $9^{\text {th }}$ grades (ages 11 to 17 ) from suburban high schools. Ethnicity was diverse: $31.8 \%$ of the sample was White, $31.6 \%$ was Black and 36.6\% was Latino. Alcohol use and parental monitoring questionnaires were used to assess the quantity of alcohol use in the last month and parents' knowledge about their children's activities. In the parental monitoring scale, seven items were related to each parent. The data collection procedure was longitudinal; teachers and youth re-reported one year later. After data collection, structural equation modeling (SEM) and hierarchical logistic regressions were used to do the analyses. Regarding the hypotheses, researchers found that compared with boys, girls received more monitoring from their mothers. Further, high levels of monitoring were significantly related to girls' lower alcohol use. Result showed that when girls received more monitoring from their mothers than boys (i.e., their mothers know where they are and their activities), girls were tended to use alcohol less frequently. This study showed that parental monitoring, especially maternal monitoring, had an effective protective influence for girls' alcohol use. 
Personal Fable, Drug Use and Parental Monitoring in Adolescents and Young Adults

Yu et al. (2006). Yu et al. (2006) developed a study focused on parental monitoring, communication between parents and children, and youth drug use as well as other risk behaviors. They wanted to explore the relationships among youth drug use, the perceptions of parent-youth communication from adolescents and their parents, and the perceptions of monitoring from both youth and parents. The hypotheses for this study was that high levels of parental monitoring and high levels of parent and youth communication would be associated with low levels of youth drug use and other risk behaviors. Participants in this study were $7526^{\text {th }}$ grade Bahamian elementary school students (46\% male, 54\% female; mean age was 10.5 years) and 647 of their parents. Measures used in this study for this issue were a parental monitoring scale and a past and future risk behavior scale (drug use and alcohol use in the past half year and in the future half year). After data collection, researchers used regression to test their hypotheses. The results showed that the youth who received high levels of monitoring from parents also reported that they anticipated engaging in lower levels of drug use in the next six months. This indicated that high level of monitoring can serve as a protect factor to influence youth's drug/alcohol use.

DiClemente et al. (2001). In one investigation, DiClemente et al. (2001) explored the association between parental monitoring and adolescents' risk behaviors, including substance use. The primary hypothesis for this study was that high levels of parental monitoring would be associated with low levels of youth substance use. Participants in this study were 522 black females ages 14 to 18 years. Alcohol/marijuana use was measured through self-report surveys and interviews. Parental monitoring was assessed by two questions about whether their parents have the knowledge of their whereabouts and friends' environments. Substance use was assessed through face-to-face interviews, in which researchers asked the participants if they had ever used marijuana and alcohol in the past 30 days. After data collection, the researchers 
Personal Fable, Drug Use and Parental Monitoring in Adolescents and Young Adults

computed logistic regressions to do the analyses and found that there was a negative relationship between parental monitoring and drug use. Results showed that participants who perceived less parental monitoring were more likely to have a history of marijuana and alcohol use in the past 30 days. The results showed that when parental monitoring was high (i.e., parents have extensive knowledge of the adolescents' whereabouts, who are their friends and what they are doing), adolescents were less likely to engage in substance use. It can be concluded that when studying youth substance use, parental monitoring is an important potential protective variable.

Fulkerson et al. (2008). In Fulkerson and colleagues' (2008) research, they tested the connections between parental monitoring and several youth risk behaviors, including alcohol use. Researchers hypothesized that parental monitoring would negatively relate to alcohol use. Participants in this study were $32506^{\text {th }}$ grade students from Chicago $(48.2 \%$ were male, $51.8 \%$ were female; mean age was 11.8 years). Their parents also participated $(78.5 \%$ were mothers, 13.1\% were fathers, $8.4 \%$ were other caregivers). The major ethnicities were African American and Latino American (more than 70\%), followed by 29.7\% Latino, and 14.8\% Caucasian. Data on alcohol use were collected from students using self-administered questionnaires about alcohol use (frequency, heaviness and intention). Parental monitoring was assessed by parents completing a monitoring scale about the monitoring level of watching $\mathrm{TV}$, listening to music, and their children's whereabouts. Data were analyzed using structural equation modeling (SEM). Results showed that high levels of parental monitoring were significantly negatively related to youth alcohol use and intentions. When parents showed high monitoring such as knowing their children's whereabouts, their kids were less likely to be engaged in alcohol use and reported lower intention to use alcohol when others offer them alcohol. It can be concluded from this study that parents monitoring behavior can serve as a protect factor to reduce youth 
Personal Fable, Drug Use and Parental Monitoring in Adolescents and Young Adults

alcohol use associated to African American and Latino American ethnic groups.

Li et al. (2000). Li et al. (2000) studied low-income African American youth as well, but they especially focused on the issue of parental monitoring and drug use, considering the influences of age and gender. Researchers wanted to find the relationships between perceived parental monitoring and health risk behaviors (e.g., drug use, unsafe sex intercourse, etc.) among low-income African American youth and children. Also, they wanted to determine if there were gender and age differences in parental monitoring. The hypotheses for this study were that, first, there would be gender and age differences in parental monitoring, such that girls and younger children (who are less than 11 years old) experienced higher levels of monitoring. Second, health risk behaviors would negatively relate to parental monitoring. Specifically, when perceived parental monitoring levels were low, the risk behaviors levels would be high. Participants in this study came from three risk reduction studies which all targeted low-income urban African American youth and children in 1992, 1994, and 1996. Respectively, samples in these three studies were 455 youth ages 9 to 15 years ( $47.7 \%$ male), 355 youth ages 9 to 17 years (48.7\% male), and 349 youth ages 9 to 15 years (56.7\% male). Monitoring was assessed by adolescents' perceptions about whether their parents have knowledge of what they are doing and where they are. Risk behaviors such as sexual risk, drug use in the past half year for the 1992 and 1994 studies were assessed by the Youth Health Risk Behavior Inventory (YHRBI), and the Child Health and Illness Profile-Adolescent Edition (CHIP-AE) in 1996. After data collection, researchers used MANOVA and Pearson correlations to analyze their data and found that the results supported the hypotheses. Generally, there were gender and age differences in parental monitoring, such that females and younger youth received more parental monitoring compared to males and older children. Also, parental monitoring was negatively related to risk behaviors. 
Personal Fable, Drug Use and Parental Monitoring in Adolescents and Young Adults

When participants reported higher levels of perceived parental monitoring, they showed lower levels of risk behaviors and were thus less engaged in these behaviors, such as unsafe sexual behavior and drug use. This study showed that when looking at youth sexual risk behavior and drug use, parental monitoring would work as an important protective factor.

Pokhrel, Unger, Wagner, Ritt-Olson and Sussman (2008). Pokhrel et al. (2008) designed their study focused on parental monitoring and substance use among Hispanic adolescents. They hypothesized that there would be a negative relationship between parental monitoring and substance use (e.g., alcohol and marijuana use in the past month) among Hispanic teenagers. Participants were 1936 high school Hispanic students (half male and half female, mean age was 14 years) from California. Data were collected through youth self-reporting parental monitoring measure (whether parents know about their activities) and a substance use scale (smoking, alcohol/marijuana use). After conducting multiple regression analyses, results confirmed the hypothesis: parental monitoring was significantly and negatively related to all kinds of substance use in the study. The result was significant after controlling for gender, age, and communication patterns between parents and children. This means that higher levels of parental control (parents know their children's activities and whereabouts) indicated lower levels of Hispanic youth's substance use in the past month and the effective function of parental monitoring has been confirmed.

Research in the current study's review not only covered different ethnic groups in the U.S such as African American, Latino, and White, but also covered studies from different cultural backgrounds and countries (e.g., Iceland).

Kristjansson et al. (2010). In Iceland, youth substance use decreased in the past decade and researchers established this study to explore if the decline is accounted by the community 
Personal Fable, Drug Use and Parental Monitoring in Adolescents and Young Adults

based intervention which was designed to increase parental monitoring (Kristjansson et al., 2010). The hypothesis for this study was that parental monitoring can account for the decline of Icelandic youths' substance use over time (e.g., alcohol use and smoking). Kristjansson et al. (2010) did a quasi-experimental design study using data from Iceland's National Youth Substance Use Surveys in 1997, 2000, 2003, 2006, and 2009 to examine this relationship in a natural setting. Three thousands one hundred and seventeen participants in the experimental group came from four places exposed to the community-based intervention designed to promote parental monitoring. The control group included 1,907 teens that were not exposed to this intervention. Results showed that parental monitoring increased in the communities that experienced the intervention and youth in the communities that have the intervention program showed decrease in drug use compared to the youth in the control group. More important, results showed that parental monitoring could account for the decrease in youth substance use during the past decade. This means that parental monitoring can serve as a protecting factor to influence youth's drug use.

Summary. According to previous research reviewed above, it can be summarized that generally there was a negative relationship between parental monitoring and youth substance use. When parents or caregivers have more knowledge of their children's whereabouts and activities, their children were less likely to engage in substance use. The results can be seen across different ethnic groups and countries (i.e., the U.S. and Iceland). In sum, previous studies provided a strong background regarding the relationship between parental monitoring and adolescents' substance use.

\section{Adolescent Egocentrism: The Personal Fable and Drug Use}

The dimension of adolescent egocentrism selected in the current study was the personal 
Personal Fable, Drug Use and Parental Monitoring in Adolescents and Young Adults

fable. Compared to the extensive literature on parental monitoring, substantially less is known about the role of the personal fable in adolescent risk behaviors, but this is particularly true regarding substance use. According to the limited body of previous research, high levels of the personal fable negatively relate to adolescent risk behaviors including alcohol and drug use (Aalsma et al., 2006; Greene et al., 2000). The relevant research on the personal fable is reviewed below. As this body of research is so scant, investigations on other risky behaviors related to drug use (e.g., delinquency) are also reviewed to support the notion that the personal fable is an antecedent of substance use.

Aalsma et al. (2006). In Aalsma et al.'s (2006) study, they focused on the relationships among adolescents' substance use behaviors, narcissism, and the personal fable. The researchers hypothesized that youth with high levels of personal fable would report high levels of smoking and drinking. Participants in this study were 561 youth from the $6^{\text {th }}$ grade $(n=94), 8^{\text {th }}$ grade $(n=$ $223), 10^{\text {th }}$ grade $(n=142)$, and $12^{\text {th }}$ grade $(n=102)$ in a city in western Canada. Among these youth, $48 \%$ were male and $52 \%$ were female and most of them were of white ethnicity and were from the lower middle and middle socioeconomic classes. Researchers in this study collected data using a personal fable scale and a risk behavior scale (e.g., alcohol use, drug use, etc.). After data collection, the authors used MANOVA and correlations to analyze their data, and found that the personal fable was associated with adolescents' substance use. Specifically, when adolescents had high levels of the invulnerability dimension of the personal fable, they were more likely to engage in substance use (i.e., alcohol and drug). Results of this study provide evidence for the notion that the personal fable is implicated in adolescent drug use involvement.

Alberts et al. (2007). In Alberts and colleagues' (2007) study, researchers focused on the relationship between the personal fable and youths' general orientation about risk taking. 
Personal Fable, Drug Use and Parental Monitoring in Adolescents and Young Adults

Hypotheses for this study were that first, the personal fable would positively increase with age, such that older youth would have higher levels of the personal fable compared to younger adolescents. Second, they anticipated that there would be a gender difference, such that males would show higher scores on the personal invulnerability dimension of the personal fable than would females. The last hypothesis was there would be a positive relationship between the personal fable and risk-taking. Participants were 119 students (55.5\% were male and 44.5\% were female) who came from middle schools in a New England town. Among the 119 students, 34 came from the $6^{\text {th }}$ grade, 41 came from the $7^{\text {th }}$ grade and 44 came from the $8^{\text {th }}$ grade. During data collection, participants self-reported on a 12-item personal fable scale and a 10-item risktaking scale. It contains two parts: a 6-item invulnerability subscale and a 6-item specialty subscale. After data collection, researchers used ANOVA and Pearson correlations to analyze their data and the results supported the hypotheses. Regarding the first hypothesis, results showed that $8^{\text {th }}$ graders had the highest total score of the personal fable and the $6^{\text {th }}$ graders had the lowest. When the two sub-dimensions of the personal fable scale were examined separately, the invulnerability score showed significant mean differences across the age groups but specialty did not. This meant that though the personal fable increased with age, the main factor that changed was the invulnerability dimension, such that older youth were more likely to feel that they could escape from danger without consequences. Regarding gender differences, the result showed that males had higher invulnerability scores compared to females. Most importantly, researchers found that the relationship between the personal fable and risk behavior was significant and positive. Specifically, when youth reported high levels of the personal fable, they were also likely to report engaging in high levels of risk-taking behaviors. This study also showed that the personal fable, especially invulnerability, was significantly related to youth risk- 
Personal Fable, Drug Use and Parental Monitoring in Adolescents and Young Adults

taking, particularly for older male youth. Results of this study showed that the personal fable was positively related to youth risk taking.

Greene et al. (2000). Greene and colleagues (2000) designed a study focused on whether the personal fable and sensation-seeking contributed to adolescents' risk-taking behaviors (e.g., drinking, drug use). Sensation-seeking, as defined in their article, is the individual's motivation to seek new or high-sensation experiences, even in the face of risk. Researchers hypothesized that both sensation-seeking and the personal fable would influence youth alcohol/drug use which means that participants who reported high levels of sensation-seeking and the personal fable also reported high levels of alcohol/drug use. Participants in this study were 724 students within the age range of $11-25$ years. In this sample, $57 \%$ were female and $42 \%$ were male (the remaining $1 \%$ did not report their gender). During data collection, participants self-reported using a personal fable scale (with three subscales of invulnerability, uniqueness and omnipotence), a sensation-seeking scale, a risk-taking personality questionnaire and a risk-taking behavior scale (e.g., smoking, drug/alcohol use and drinking while driving). After data collection, researchers used t-tests, ANOVA, correlations and regressions to analyze their data, and results showed that when high levels of the personal fable (especially high levels of invulnerability) worked together with high levels of sensation-seeking, youth were more likely to show high levels of drug and alcohol use. This meant that when youth were highly motivated to seek sensation and reported high levels of the personal fable, especially feelings of invulnerability, they were highly likely to engage in risk behaviors such as alcohol/drug use. This indicated that personal fable is positively related to youth alcohol/drug use.

Omori and Ingersoll (2005). Omori and Ingersoll (2005) studied Japanese college students’ risk behaviors (i.e., drug use, unsafe sex and drinking behavior) and focused on several factors 
Personal Fable, Drug Use and Parental Monitoring in Adolescents and Young Adults

including adolescent egocentrism (both the personal fable and the imaginary audience). The hypothesis for their research was that egocentrism would influence youth drug/cigarette use and other kinds of risk behaviors such as drinking. Omori and Ingersoll (2005) completed their research and analysis data by using 808 (42\% female, 57\% males, mean of age was 19) Japanese college age students' self-report questionnaires. Questionnaires included an Imaginary Audience Scale, a Personal Fable Scale and a measure focused on youth drug use and other risk behaviors. For drug use, participants were asked to report the age of first usage, use experience (five levels, ranging from never smoked to smoke regularly) and past month's/year's engagement frequency. After data collection, researchers used SEM to analyze the data and the results supported their hypothesis that egocentrism (imaginary audience and personal fable) predicted youth drug use and other risk behaviors. This means that when adolescents had higher scores of feeling special and invulnerable, they were more likely to engage in drug use.

Arnett (1990). Arnett (1990) is one of the early researchers who explored the factor of adolescent egocentrism in a study of youth risk behavior, in this case, drunk driving. In this research, Arnett (1990) looked at egocentrism as a whole to study the issue of drunk driving. The hypothesis for the study was that males' drunk driving would be positively related to egocentrism. The participants were 181 male high school students aged 17 and 18. Egocentrism was measured by four questions designed to determine whether the boys underestimate the risk of drunk driving or not. The study measured how many times participants drove after drinking in the last six months to one year. Results confirmed the hypothesis; there was a significant positive relationship between egocentrism and drunk driving. The study found that participants who had a higher level of drunk driving showed higher scores on egocentrism, which means they were less likely to believe that drunk driving would cause an accident. 
Personal Fable, Drug Use and Parental Monitoring in Adolescents and Young Adults

Although the above research indicated that there was a relationship between the personal fable and drug use or other related risky behaviors, some other studies have contradictory findings. In particular, there are two additional studies in which the link between the personal fable and substance use was not significant. These studies are described below.

Bright et al. (2008). Bright et al. (2008) designed a study to explore whether there was a relationship between the personal fable and youth smoking situations (ex-smokers, current smoker, never smoked). Specifically, they expected that currently smoking youth would have higher levels of the personal fable than those who had never smoked and those who were exsmokers. The participants were 249 university students ( $3 / 5$ of the sample was female) from Australia, with ages ranging between 17 to 25 years old. Data were collected through participants' self-report on a personal fable scale and if they were ex-smokers, current smokers, or never smoked. As opposed to other studies that the personal fable and substance use has a positive relationship, after data analysis, results of this study found there was no significant relationship between personal fable and smoking behavior. The author mentioned the reason of the non-significant finding might be that in this study, the researchers separated smokers from ex-smokers, those who had never smoked and current smokers instead of just looking at smoking behavior as a whole. In sum, this result challenged the idea that the personal fable can be used to explain youth smoking behavior.

Frankenberger (2004). Another piece of research completed by Frankenberger (2004) was about adolescents' egocentrism and smoking behavior among United States teenagers also contradicted that there was a relationship between the personal fable and substance use. In Frankenberger's (2004) research, it was hypothesized that a relationship would exist between egocentrism and youth smoking behavior, such as youth who have higher scores on the personal 
Personal Fable, Drug Use and Parental Monitoring in Adolescents and Young Adults

fable would show higher levels of smoking behavior. To test the hypothesis, Frankenberger (2004) collected self-report data from 215 (almost half female and half male) high school teenagers. Measurements included a personal fable scale, a risk perception scale (which tests youths' risk evaluations about smoking behaviors), and a smoking frequency measure. After statistical analysis, the results rejected the assumption of the association between personal fable and smoking behavior. The study indicated that there was no significant relationship between the personal fable and smoking behavior which means that when a youth shows higher levels of personal fable and felt invulnerable, he/she did not tend to become more engaged in smoking behavior at the same time.

Summary. According to the studies above, it can be seen that there were contradictory results regarding the relationship between the personal fable and drug/alcohol use. Some researchers found that the personal fable was positively related to youth drug use and other risk behaviors (Alberts et al., 2007; Omori \& Ingersoll, 2005) while other researchers did not. Both Bright et al.'s (2008) and Frankenberger's (2004) studies found that the relationship between the personal fable and youth smoking behavior did not significantly exist. The contradictory studies both focused on smoking behaviors. It might be possible that the personal fable can only explain variables in some kinds of substance use, such as alcohol, but not every types of substance (i.e., smoking). Another reason for the contradiction might be a measurement issue, in that some of the studies reviewed above used the old version of the personal fable scale (i.e., Arnett, 1990) that did not separate three sub-dimensions of personal fable, while others used the new version personal fable scale (e.g., Bright et al., 2008). Since the findings of the relationship between personal fable and youth drug use has contradictory results, it is important for the current study exploring this relationship and providing more evidence about whether the association between 
Personal Fable, Drug Use and Parental Monitoring in Adolescents and Young Adults

personal fable and youth drug use significantly exist or not.

\section{Parental Control as a Moderator}

An additional goal of the current study was to explore whether parental monitoring moderates the effect of the personal fable on adolescent drug use. The interaction of parental monitoring and youth personal fable has not been studied in previous studies, but the conceptual rationale for this association is described below, illustrated by literature on related topics.

Socialization absolutely influences an individual's development heavily. Parents are the most important direct factor that affect young children and adolescents in the social environment system of Jessor and Jessor's (1977) problem behavior model. The way parents treat or educate their children will influence their children and their behaviors. When children grow up and enter the stage of adolescence, they become more interactive with peers and might be less interactive with parents. However, research showed that parents' influence still mattered for youth's risk behavior or drug use. Parental monitoring can serve as a moderator for relationships between youth risk behavior and associate with risk-taking peers: when youth received high levels of parental monitoring, they tended to show lower levels of risk taking even they have some risktaking peers (Wood, Read, Mitchell \& Brand, 2004). It is possible that parents' knowledge of children's whereabouts and activities can serve as a moderator, influencing the relationship between adolescents' personal fable and risk behavior. This means that the youth might be less likely to be engaged in drug use when their parents have knowledge of their whereabouts and activities, no matter what levels of personal fable they have.

Wood et al. (2004). In Wood and colleagues' (2004) study, researchers focused on both peers' and parents' influences on youth risk behaviors. Specifically, in their study, parental monitoring was conceptualized as a protective factor, which may protect adolescents from 
Personal Fable, Drug Use and Parental Monitoring in Adolescents and Young Adults

engaging in risk behaviors. The hypotheses for this study were that first, youth would show more heavy drinking behavior if their peers engaged in high levels of alcohol use behaviors and offered them alcohol. The second hypothesis was that parental monitoring would influence the relationship between peer influence and youth alcohol use. In other words, for youth who received high parental monitoring, even when they were exposed to peers who used alcohol and offered them alcohol, they would show low levels of engagement in alcohol use compared to youth with low parental monitoring who had alcohol-using peers. In their research, 556 older adolescents who had just finished high school participated in the study (56.1\% female, $43.9 \%$ male, aged from 18 to 19$)$, and the ethnic majority was White (87\%). Surveys used in this study included an alcohol offers scale, a parental monitoring scale, a heavy alcohol use scale and an alcohol-related negative outcomes scale (e.g., loss of memory). After data collection, the authors used hierarchical regression analyses and they found that peers' behaviors were associated with youth alcohol use. It indicated that youth who had alcohol-using peers and received alcohol offers from peers, they were more likely to engage in drinking behavior. However, more importantly, this study found that parents' variables moderated the relation between drinking peers and teens' alcohol use. When youth had alcohol-using peers but received high monitoring from parents, they were less likely to engage in alcohol use compared to the youth who had drinking peers but did not receive high monitoring from their parents. This study provides some support for the notion that parental monitoring may serve as a moderator of the association between important antecedents and risk behaviors.

The reviews above indicated the importance of parental monitoring and the personal fable. These two variables both associated with youth drug use and generally, when youth received 
Personal Fable, Drug Use and Parental Monitoring in Adolescents and Young Adults

high levels of parental monitoring or have low levels of personal fable, they tended to show lower levels of drug use.

\section{Hypotheses}

Based on problem behavior theory, the personal fable (personality system), parental monitoring (perceived-environment system), and drug use (risk behaviors) are the focus of the current study. There are three hypotheses tested in the current study based on problem behavior theory and the personal fable.

First, as suggested by existing research on parental monitoring and risk behavior (e.g., Fulkerson et al., 2008; Kristjansson et al., 2010; Li et al., 2000), adolescents who receive high levels of parental monitoring (perceived-environmental system) will be less likely to engage in lifetime and current substance use than teens with low levels of parental monitoring.

Second, consistent with the evidence described above (e.g., Alberts et al., 2007; Greene et al., 2000; Omori \& Ingersoll, 2005), adolescents who have high personal fable scores (personality system) will engage in higher levels of lifetime and recent drug use than teens with low personal fable scores.

Third, as described in the aforementioned conceptual rationale, it is hypothesized that parental monitoring will interact with the personal fable in predicting drug use. Based on previous research, parental monitoring can negatively relate to youth drug use (Kristjansson et al., 2010; Li et al., 2000), and can also influence the relationship between youth drug use and other correlates (Wood et al., 2004). Thus, it is expected in the current study that the interaction of parental monitoring and personal fable would predict youth lifetime and recent drug use. Since there was wide age range in the sample and the participants were come from two different resources, age groups would be considered as a control variable. In addition, it is expected that 
Personal Fable, Drug Use and Parental Monitoring in Adolescents and Young Adults

when youth have high levels of parental monitoring and low level of personal fable, they will be engage in the lowest level of drug use compared to the youth who have high levels of personal fable and high levels of parental monitoring, youth who have low levels of the parental monitoring and low levels of personal fable, and the youth who have low levels of parental monitoring and high levels of personal fable. 
Personal Fable, Drug Use and Parental Monitoring in Adolescents and Young Adults

\section{CHAPTER 3}

\section{METHOD}

\section{Participants}

A total of 56 students participated in this study. Twenty five of the participants were ages 12 to 18 years old $(M=14.6 ; S D=1.64$, see Table 1$)$, and came from a small, suburban Midwestern school district in southern Michigan. The remaining 32 participants were ages 18 to 22 years old $(M=19.03 ; S D=1.13)$, and were students enrolled in child development classes at West Virginia University. $61 \%$ of the college sample participants lived with both biological parents.

Thus, the age range of this sample is wide from 12 to 22 years, and among these participants, $87.5 \%$ were female and $94.6 \%$ were Caucasian. In the high school sample, $32.0 \%$ of the participants were in the $11^{\text {th }}$ grade, $24.0 \%$ were in the $10^{\text {th }}$ grade and $24.0 \%$ were in the $8^{\text {th }}$ grade. In the college sample, $45.2 \%$ of the participants were first-year students, $22.6 \%$ were in second year, $22.6 \%$ were in third year and $9.7 \%$ were in fourth year. More specific descriptions of each subsample are shown in Table 1.

\section{Procedures}

For both samples, study data were collected through online survey tool called Survey Monkey. Slightly different procedures were followed for the youth and college samples, and these will be explained separately below.

Youth sample. First, an introduction letter that simply explained the current study was sent to the parents of all eligible students in the selected middle school and high school in Michigan. After parents agreed that their children could participate, researchers sent a website link and a unique login ID to their children's email addresses or by postal mail. Then, youth logged in to 
Personal Fable, Drug Use and Parental Monitoring in Adolescents and Young Adults

the online survey system using their unique ID, and answered the study questionnaires. During the online survey, participants could skip questions they did not wish to answer or stop at any time. Youth who answered at least $80 \%$ of the survey questions received a $\$ 10$ gift card by mail.

College sample. Due to limited responses from the middle and high school students, this study also collected data from college students in West Virginia University using the same measurements. Students who were enrolled in CDFS 110: Families Across the Lifespan were invited to participate in this study, provided that they had lived at home with their parent(s) in the previous 2 months. After the study was approved by the West Virginia University IRB and the instructors of each section of CDFS 110, a researcher went to each class, did a short presentation about this study, and left invitation letters with instructions about how to do the online survey. Students who took part in the study were ages 18 years or older and had lived with parents during the past two calendar months. During data collection, participants could skip any questions, drop out at any time, or choose "do not wish to answer" for any item. The collection procedure in the college sample was entirely anonymous and voluntary: no identifying information was collected and no study compensation was provided.

\section{Measures}

There were four questionnaire measures included in the current study. These included (a) a demographic survey; (b) a personal fable scale to test children's feelings of specialty, uniqueness and invulnerability; (c) a parental monitoring questionnaire about whether children think that their parents have knowledge of their whereabouts and activities; and (d) a drug use survey. A detailed description of each measure is provided below.

Demographics. Participants completed a demographic survey (see Appendix A for middle/high school, Appendix B for college), which included questions about their age, sex, 
Personal Fable, Drug Use and Parental Monitoring in Adolescents and Young Adults

ethnicity, who they live with, and family income (if known).

Personal fable scale. Adolescents completed the 12-item continuous personal fable scale (see Appendix C) developed by Alberts and colleagues in 2007 (original sample $\alpha=.60$; Alberts et al., 2007). It was used to assess participants' feelings of specialty and being invulnerable. This scale has two subscales: specialty and invulnerability. Six items were used to comprise specialty (e.g., "Sometimes when I see a good-looking girl/boy, I think that they are looking at me in a very admiring way,") and six items were used to represent invulnerability (e.g., "Some kids believe that they don't need to put on their seatbelt every time they get in a car"). The response scale consists of a 5-point Likert scale ranging from 1 (Never true for me) to 5(Always true for me). Scores were calculated by adding all the answers together. All items were included in the overall personal fable scale score and the score ranges from 12 to 60 . This is a continuous scale and high scores indicate high levels of the personal fable. Alberts et al. confirmed this measure's validity in their research of the personal fable and youth risk taking (Alberts et al., 2007). The Cronbach's alpha for the subscale of specialty was .38 for middle/high school sample and .03 for college sample. Two items in specialty subscale were negatively related to each other (i.e., "When my parents or friends tell me that they know how I feel, I don't believe that they really do," and "Sometimes when I see a good-looking girl/boy, I think that they are looking at me in a very admiring way.") These two items seemed to be representing a different concept compared to other items that more directly measure specialty. The Cronbach's alpha for invulnerability was .65 for the middle/high school sample and .57 for the college sample. Overall, the total scale demonstrated adequate internal consistency in the current sample (full sample Cronbach's $\alpha=.61$; middle/high school sample $=.64$; college sample $=.62$ ).

Parental monitoring scale. The parental monitoring scale (see Appendix D) developed by 
Personal Fable, Drug Use and Parental Monitoring in Adolescents and Young Adults

Stattin and Kerr (2000) was used to assess parents' knowledge of their children's whereabouts and activities. Adolescents completed this measure by answering whether their parents know their whereabouts and activities. This is a nine-item continuous scale, and example items include "Do your parents know who you have as friends during your free time?" and "Do your parents know what you do during your free time?" Youth responded to each item using a 5-point Likert scale, and the answers ranged from 1 (Strongly disagree) to 5 (Strongly agree). Scores were calculated by adding the responses for each item together ranges from 9 to 45 and high scores indicated high levels of parental monitoring. This scale's internal consistency has been established in Stattin and Kerr's (2000) research $(\alpha=.86)$. In the full sample, this scale's internal consistency was good (Cronbach's $\alpha=.88$ ). In addition, the Cronbach's alpha for the middle/high school sample was .56, and for the college sample, it was .91.

Drug use survey. A continuous scale assessed youth drug use (see Appendix E) with items selected from the Youth Risk Behavior Survey (Centers for Disease Control and Prevention, 2010) used in this study. Both lifetime use experience and recent usage were assessed in this survey. Substances included alcohol, cigarettes, marijuana, sniffed glue, cocaine, heroin, methamphetamines, ecstasy, hallucinogenic drugs, steroid pills or shots without a doctor's prescription, and prescription drugs without a doctor's prescription. Scores were calculated by summing all the items together.

For lifetime usage, participants only needed to answer Yes or No to indicate whether they had any experience using these substances. Example items for lifetime usage are: "In your lifetime, have you ever tried or used any form of cocaine, including powder, crack or freebase?" and "In your lifetime, have you ever tried or used any form of alcohol, more than just a sip or two (e.g., beer, wine, or liquor)?" To assess the past month's usage, youth answered on how 
Personal Fable, Drug Use and Parental Monitoring in Adolescents and Young Adults

many days during past 30 days $(0,1-2,3-5,6-9,10-19,20-29$, All 30) they used each substance. An example item for recent drug use is: "During the past 30 days, on how many days did you smoke cigarettes?" This drug use measure is a continuous one and scores were calculated by adding each item together. Score range for lifetime drug use is from 0 to 21 , and for recent drug use is from 0-42. Higher scores indicated high levels of lifetime and recent drug use. In the current study, students only reported using cigarettes, chewing tobacco, cigars, alcohol, marijuana, and prescription medicine without a doctors' prescription, nobody used other drugs. In the full sample, the lifetime drug use scale's internal consistency was good (Cronbach's $\alpha$ $=.79$ ). When looking at alphas for separated samples in lifetime drug use, due to the items had zero variance, the alpha could not be calculated for the middle/high school sample, but the Cronbach's alpha for the college sample was .72. For the recent drug use scale, only the items about cigarette, alcohol and marijuana use were used to create the recent drug use scale score, as no participants indicated they had recently used any of the other substances. This composite score was entered into the final analysis and the scale's internal consistency was good (Cronbach's $\alpha=.52$ ).

\section{Analytic Strategy}

The first hypothesis was that higher parental monitoring scores would be related to lower levels of substance use frequency. To test the first hypothesis about the relation between parental monitoring and substance use, Pearson's correlations were used. The second hypothesis was that higher levels of personal fable would be related to higher levels of substance use frequency. To test the second hypothesis, Pearson's correlation used. The third hypothesis was that parental monitoring would interact with the personal fable in predicting substance use. Specifically, it was expected that high parental monitoring combined with low personal fable 
Personal Fable, Drug Use and Parental Monitoring in Adolescents and Young Adults

would predict the lowest level of youth drug use, while low parental monitoring combined with high personal fable would predict the highest levels of youth drug use. To test this moderation hypothesis, hierarchical regression and ANOVA were used. In regression analysis, parental monitoring and personal fable were entered at the same time. Since the sample was combined by two groups of participants from a middle school, a high school and a college and has a wide range of age from 12 to 22 years, the current study controlled the sample variable in regression analysis. It was categorized that group " 0 " for high school and middle school students and group " 1 " for college students. Prior to conducting the regression analyses, mean differences between the two groups on all study variables were examined. In the ANOVA test, participants were categorized into four groups: (a) high monitoring/high personal fable group, (b) high monitoring/low personal fable group, (c) low monitoring/high personal fable group, and (d) low monitoring/low personal fable group, based on whether their scores for parental monitoring and the personal fable were above or below the median for each variable. 
Personal Fable, Drug Use and Parental Monitoring in Adolescents and Young Adults

\section{CHAPTER 4}

\section{RESULTS}

\section{Correlation Analyses}

The first purpose of this study was to test the relationship between parental monitoring and youth drug use. It was hypothesized that high levels of parental monitoring would be related to low levels of drug use. This aim was tested by Pearson's correlation coefficient analysis (see Table 2). Results in the table support the first hypothesis in the expected direction. High levels of parental monitoring were significantly and negatively related to both lifetime drug use, $r$ (48) $=.47, p<.05$, and recent drug use, $r(48)=-.38, p<.05$. The results indicated that youth had low levels of both lifetime and recent drug use when parental monitoring levels were high.

The second aim of the study was to explore the association between personal fable and drug use. It was expected that high levels of personal fable would positively relate to high levels of youth drug use. This direction was analyzed by using Pearson's correlation coefficient (see Table 2). It can be seen from Table 2 that the results did not support the second hypothesis. Neither lifetime drug use, nor recent drug use were positively related to youth personal fable. The correlation was not significant for the relationship between personal fable and lifetime drug use, $r(47)=.15, p=.31$, nor for the association of the personal fable and recent drug use, $r$ (47) $=.03, p=.82$. These results indicate that high levels of youth personal fable were not significantly associated with higher youth lifetime and recent drug use.

\section{Regression Analyses}

The third hypothesis of this study was that parental monitoring would interact with the personal fable in predicting youth drug use. To test the last hypothesis, two hierarchical regressions were completed to predict both youth lifetime drug use and recent drug use. Since 
Personal Fable, Drug Use and Parental Monitoring in Adolescents and Young Adults

participants came from two groups and age is a control variable, an ANOVA analysis was completed to explore the potential difference in the two groups. It was revealed that the two groups significantly differed in parental monitoring, $F(1,46)=6.45, p<.05$, such that the middle school and high school group $(M=37.50 ; S D=3.60)$ had higher levels of monitoring than the college group $(M=32.30 ; S D=8.20)$. They also differed in terms of lifetime drug use, $F(1,48)=35.80, p<.05$, such that the middle school and high school group $(M=0.20 ; S D=$ 0.41) had lower levels of lifetime drug use than the college group $(M=2.47 ; S D=1.66)$. Finally, they also differed in terms of recent drug use, $F(1,48)=16.49, p<.05$, such that the middle school and high school group $(M=3.25 ; S D=0.91)$ had lower levels of recent drug use than the college group $(M=5.87 ; S D=2.78)$. There was no significant age difference in the personal fable, $F(1,49)=.03, p=.86$. Given these group differences, the sample was entered as the controlled variable in the subsequent regression analyses.

For the regression analyses, youth lifetime drug use and recent drug use were dependent variables, while the sample variable was entered as the first step, and the personal fable and parental monitoring scores were entered as the second step. To investigate the potential moderating factor of parental monitoring on the association of personal fable and youth drug use, the interaction of parental monitoring and the personal fable were entered as the third step. Centered terms were used to calculate the interaction between these two variables.

Lifetime drug use. In the first step of this regression model for lifetime drug use, the sample accounted for a significant portion of the variance in youth lifetime drug use, $F(1,44)=$ $27.36, p<.05, R^{2}=.38$ (see Table 3 ). This means the sample variable can account for $38 \%$ of the variance in youth lifetime drug use and the participants' lifetime drug use is different whether they were in middle school and high school, or college. Participants from college showed more 
Personal Fable, Drug Use and Parental Monitoring in Adolescents and Young Adults

lifetime drug use than those who came from middle school and high school. The addition of the independent variables of the personal fable and parental monitoring on the second step improved the significant portion of the variance explained in youth lifetime drug use, $\Delta F(2,42)=3.29, p$ $<.05, \Delta R^{2}=.08$. College students had higher levels of lifetime drug use than younger students, and youth with low levels of parental monitoring reported high levels of youth lifetime drug use. The personal fable was not a significant predictor of lifetime drug use. In the last step of the regression, the interaction of personal fable and parental monitoring failed to account for any additional portion of the variance in youth lifetime drug use, $\Delta F(1,41)=.43, p=.52, \Delta R^{2}=0$. The interaction between parental monitoring and the personal fable did not predict youth lifetime drug use.

Recent drug use. In this regression model, the sample was accounted for a significant portion of the variance in youth recent drug use, $F(1,44)=12.54, p<.05, R^{2}=.22$ (see Table 4). This means the sample variable can account for $22 \%$ of the variance in youth recent drug use. College students tend to be more engaged in recent drug use than the middle school and high school group. The additional independent variables of personal fable and parental monitoring in the second step failed to improve the significant portion of the variance in youth recent drug use, $\Delta F(2,42)=1.74, p=.19, \Delta R^{2}=.06$. Although the sample remained a significant predictor of recent drug use, neither the personal fable nor parental monitoring was associated with levels of recent drug use. In the last step of the regression, the interaction of the personal fable and parental monitoring failed to account for any additional portion of the variance in youth recent drug use, $\Delta F(1,41)=3.22, p=.08, \Delta R^{2}=.05$. The interaction between youth personal fable and parental monitoring did not predict youth recent drug use.

\section{ANOVA Analysis}


Personal Fable, Drug Use and Parental Monitoring in Adolescents and Young Adults

An ANOVA was conducted in order to further explore the potential moderation of parental monitoring and the personal fable on substance use. Participants were categorized into four groups based on whether their scores for parental monitoring and the personal fable were above or below the median for each variable. There were 8 youths in the high monitoring/high personal fable group, 17 teens in the high monitoring/low personal fable group, 16 in the low monitoring/high personal fable group, and 5 in the low monitoring/low personal fable group. It was revealed that there was a significant difference among the four groups in youth lifetime drug use, $F(1,3)=3.12, p<.05, \eta^{2}=.18$. This means the different groups account for $18 \%$ of the variance in youth lifetime drug use. Youth's lifetime drug use was different when they reported different levels of parental monitoring and personal fable. To further explore the difference, post hoc comparisons were completed with least significant difference pairwise multiple comparison tests. Youth in the low monitoring/high personal fable group reported higher levels of lifetime drug use $(M=2.56, S D=1.90)$ than youth in the high monitoring/high personal fable group $(M$ $=.88, S D=1.36)$ and the high monitoring/low personal fable group $(M=1.12, S D=1.50)$. Though there was no statistically difference among the other groups, it was still hinted from the mean that youth in the low monitoring/low personal fable group showed higher levels of lifetime drug use $(M=2.20, S D=1.30)$ than youth in the high monitoring/high personal fable group and the high parental monitoring/low personal fable group. There were no significant differences among four groups regarding youths' recent drug use, $F(1,3)=2.72, p=.06$. 
Personal Fable, Drug Use and Parental Monitoring in Adolescents and Young Adults

\section{CHAPTER 5 \\ DISCUSSION}

The purpose of this study was to explore the relations among the personal fable, drug use and parental monitoring in adolescence. It was expected that when youth had high levels of the personal fable and low levels of parental monitoring, they would be more likely to engage in drug use. Furthermore, it was also expected that parental monitoring would serve as a moderator by interacting with the personal fable to predict youth drug use, such that high levels of parental monitoring combined with low levels of the personal fable would lead to lower levels of youth drug use. The results partially supported the hypotheses. The current study showed that parental monitoring was negatively and significantly related to youth drug use, and there was partial support for the hypothesized moderation effect. However, the remaining hypothesis about the personal fable and youth drug use was not supported.

\section{Parental Monitoring}

The first hypothesis was that high levels of parental monitoring would negatively relate to youth drug use. This hypothesis was supported by the result in the expected direction. High levels of parental monitoring were negatively associated with low levels of lifetime and recent drug use. This means that when the parents have more knowledge of their children's whereabouts and activities, their children were less likely to engage in drug use such as alcohol, chewing tobacco, marijuana, etc. This finding was consistent with previous studies completed by Shillington et al. (2005), Beck et al. (2003), Webb et al. (2002), and Fulkerson et al. (2008). The current study had similar findings to Shillington and colleagues' (2005) research that high levels of parental monitoring were negatively associated with high-risk youth's recent and lifetime use of drugs, such as alcohol and cigarettes. Also, the current study was consistent with 
Personal Fable, Drug Use and Parental Monitoring in Adolescents and Young Adults

the finding in Beck and colleagues' (2003) research that youth who had parents who have more knowledge of their activities tended to show less drinking behavior. The relation between parental monitoring and youth drug use in the current study provides evidence that parental monitoring is an important factor that helps to limit or reduce youths' drug use. Several potential mechanisms may explain this effect: When parents have knowledge of their children's activities, who they are hanging out with, what they are doing after school, etc., their children have less time and fewer possibilities to hang out with risky children who use drugs or to try drugs, and these lead to low levels of youth drug use (Bahr, Hoffmann \& Yang, 2005; Wood et al., 2004). Also, high quality relationships and involvement between parents and the youth, and youth's emotional attachment to their parents make the adolescents more likely to talk about themselves to their parents initiatively and this discourse is an important source of parental monitoring (Kerr \& Stattin, 2000; Laird, Pettit, Bates, \& Dodge, 2003a). In addition, when parents and children have good relationships, the children would be less likely to do things that might destroy the relationships or to make their parents disappointed (Kerr \& Stattin, 2000).

Not only can low parental monitoring lead to drug use, but drug use can predict parental monitoring as well. Though the current study can not tell the direction of parental monitoring and youth drug use, according to Laird et al.'s (2003a) study, this relationship might be bidirectional. Youth delinquency can predict low levels of parental monitoring (Laird et al., 2003a). When adolescents have high levels of delinquency or antisocial behavior, it usually links to a negative parent-children relationship and parents and children might spend little time together and communicate poorly. In this case, parents might become less knowledgeable of their children's lives (Laird, Pettit, Bates, \& Dodge, 2003b). Parents might also tend to withdraw from monitoring their children in order to avoid the negative relationship. Moreover, when 
Personal Fable, Drug Use and Parental Monitoring in Adolescents and Young Adults

parents have a negative relationship with their children or their children were engaged in delinquency behaviors, they might feel embarrassment talking about their children and try to avoid getting the information of their children from others such as teachers or other parents (Laird et al., 2003a).

\section{The Personal Fable}

The second hypothesis was that high levels of personal fable would be positively related to drug use. This hypothesis was not supported by the study's results, which revealed no associations between the personal fable and either lifetime $(p=.31)$ or recent drug use $(p=.82)$. The non-significant finding means that even when youth had high levels of the personal fable and thought that they were invulnerable and special, they did not show more lifetime or recent use of alcohol, tobacco in any form, prescription medicine without a doctors' prescription, or marijuana than did their peers who reported low levels of the personal fable. This nonsignificant result was inconsistent with previous study completed by Alberts and colleagues (2007). In Alberts and colleagues' (2007) study, there was a positive relationship between youths' personal fable and risk taking. When adolescents have high levels of the personal fable and think they are invulnerable and special, they tend to report high levels of risk taking behaviors (Alberts et al., 2007).

Although the current study's result was inconsistent with some previous research, the nonsignificant finding of youth personal fable and drug use was consistent with some other studies. In Bright and colleagues' (2008) study, there was no significant relation between adolescents feeling invulnerable and special, and their use of drugs. The situation was the same in Frankenberger's (2004) study. The non-significant finding of the current study provides support to the previous studies that did not find the connection between the personal fable and youths' 
Personal Fable, Drug Use and Parental Monitoring in Adolescents and Young Adults

substance use.

There are multiple reasons for the non-significant finding in this study. First, the small sample size may be the culprit. Due to the short study time and low response rate in both the middle/high school and college samples, the current study ended up with only 56 participants and this number is much smaller than other studies (e.g., 808 students in Omori and Ingersoll's study in 2005). With such small correlations between the personal fable and drug use, post-hoc power analyses suggested that 350 participants would be needed in order to have a reasonable chance of detecting such small effects (Cohen, 1988). Second, the majority of participants in the current study were female (76\% in the middle/high school sample and $97 \%$ in the college sample) but other studies tended to have equal gender distributions (e.g., Alberts et al., 2007; Omori \& Ingersoll, 2005). In addition, it was mentioned in Alberts and colleagues' (2007) study that boys tended to score higher than girls on the feeling of personal invulnerability fable subscale and this indicated a possibility that gender might be a moderator of personal fable on youth drug use.

The third potential reason might be the wide age range; the personal fable might matter for one age but not for others. The current study had a wide age range, from ages 12 to 22 years but other studies tended to have younger participants. For example, in Alberts and colleagues' (2007) study, participants were from $6^{\text {th }}$ grade, $7^{\text {th }}$ grade, and $8^{\text {th }}$ grade. It might be that the personal fable matters more or is more significant for some ages than another. In Alberts et al.'s (2007) study, the highest level of personal fable emerged at $8^{\text {th }}$ grade compared to the $6^{\text {th }}$ and the $7^{\text {th }}$ grade, which means students in $8^{\text {th }}$ grade tended to feel more invulnerable and special. As mentioned in the background information in their study, Alberts et al. (2007) indicated that the developmental process of personal fable is a curvilinear trend, which increases in the early 
Personal Fable, Drug Use and Parental Monitoring in Adolescents and Young Adults

adolescence and decreases in the late adolescence (Alberts et al., 2007). Moreover, the difference might be due to youth's different cognitive development stages. According to Piaget's cognitive theory, when adolescents begin to start the formal operational stage, they cannot successfully handle the ability of distinguishing subject and object so it might be hard for them to distinguish the difference between their own point of views and the thoughts of other people, which represents the personal fable (Alberts et al., 2007; Piaget, 1970). When they get more mature, they are more skilled in taking others' perspectives and this explains the decrease of the personal fable (Piaget, 1970). This evidence means that the personal fable is more likely to be significant during early to mid adolescence than in late adolescence or emerging adulthood, the period covered in the current study.

In addition, it might be that personal fable was more important to certain types of drugs but not all types of drugs. Both Bright and colleagues (2008) and Frankenberger (2004) were primarily focused on smoking behavior and the relationship of personal fable and smoking behavior was not significant. Therefore, it indicated that personal fable might be more important for drugs such as alcohol, but not for other types of drug use, such as cigarettes.

\section{Parental Monitoring as a Moderator}

The last aim of this study was to test whether parental monitoring moderated the effect of the personal fable on drug use. Hierarchical regressions and ANOVA were used in the analytic procedure. Results from the regression analysis did not support this hypothesis for either lifetime or recent drug use. The results from the regression analysis indicated that parents' knowledge of children's whereabouts and activities did not interact with the youth's feelings of invulnerability and specialty to predict youths' lifetime $(p=.52)$ or recent drug use $(p=.08)$. Though the results showed that parental monitoring did not interact with the personal fable to 
Personal Fable, Drug Use and Parental Monitoring in Adolescents and Young Adults

predict youth drug use, these two variables did relate to each other in a negative way. This means that when youth had high levels of the personal fable, they tended to have low levels of parental monitoring. Though there was no previous research studied directly on this negative correlation, it might be possible that when youth have high levels of personal fable and think they are invulnerable and special, they tend to appear to be blinded confident. Which might misleading the parents, who might think their children were safe and decrease their monitoring level.

In order to further explore the potential effect of the moderation of parental monitoring, an ANOVA was ran to compare the substance use means of four groups: high monitoring/high personal fable group; high monitoring/low personal fable group; low monitoring/high personal fable group, and low monitoring/low personal fable group. The results of the ANOVAs showed that there were some significant group differences in lifetime drug use but not for recent drug use, which means youth lifetime drug use differed when they have different levels of parental monitoring and the personal fable. To further explore where the differences were, a post hoc analysis was completed.

The results showed that youth who reported low levels of monitoring and high levels of the personal fable tended to have higher levels of lifetime drug use, compared with the adolescents who received high levels of parental monitoring and high levels of personal fable, and the youth who received high levels of parental monitoring and had low levels of the personal fable. In addition, there was a hint that the youth who received low levels of parental monitoring and had low levels of the personal fable tended to have higher levels of lifetime drug use compared to teens who had high levels of the personal fable and received high levels of parental monitoring, and the youth who received high levels of parental monitoring and have low levels of personal 
Personal Fable, Drug Use and Parental Monitoring in Adolescents and Young Adults

fable. Moreover, these results combined together hinted that personal fable did not independently influence youths' lifetime drug use but this effect was dependent on the level of parental monitoring. It can be seen in Figure 2 that low levels of parental monitoring exacerbated the relation between the personal fable and lifetime drug use. Youth tended to have higher levels of drug use when they received low levels of parental monitoring (see Figure 2). This result provided suggestion about the possibility of a moderation effect of parental monitoring.

Since there were no previous studies focused on whether parental monitoring moderated the relation between the personal fable and youth drug use, it is not possible to compare the findings of the current study to others in the literature. The potential reason of why the regression analysis failed to support parental monitoring as a moderator might be the small sample size. The sample size was too small to get a significant main effect for the personal fable in predicting youth drug use, which makes it even harder to find a significant interaction of the personal fable and parental monitoring. In addition, there might be other factors influencing the effects of parental monitoring or personal fable in their relations with youth drug use, such as self-regulation. Selfregulation refers to the cognitive function that is related to control youth's internal drive to engage in risk taking behaviors when study youth risk behaviors (Percy, 2008). It was showed that youth who have good self-regulation tended to engaged in less substance use (Percy, 2008). It might be that when parents show more acceptance and support, their youths tend to regulate themselves better and have the good relationships with the parents (Morris, Silk, Steinberg, Myers, \& Robinson, 2007). Therefore, their parents tend to have more knowledge about their activities. Also, it might be that the well-regulated youth can control their internal drives better and realize the harmful effects of drugs, so they feel less invulnerable and are less likely to use 
Personal Fable, Drug Use and Parental Monitoring in Adolescents and Young Adults

drugs.

Though the results from regression did not find the moderation effect of parental monitoring, the ANOVA analysis hinted at a possible moderation effect. Results from the ANOVA analysis showed that when parents have more knowledge of their children's whereabouts and activities, and at the same time, their children were less likely to think they are invulnerable and special, lifetime drug use was less likely to appear in the adolescents. Also, it could be that parents of adolescents in high monitoring/high personal fable group know their children might be engaged in risk taking so they tried to get more knowledge of their children's activities to protect them. The reason of the different outcomes from regression and ANOVA might because that the regression analysis was based on the continuous predictor while ANOVA tended to predict the outcomes based on categorical predictor.

\section{Limitations and Future Directions}

The first limitation of the current study was sample size. Only 56 students participated in this study and this number is too small to get significance according to power analysis (Cohen, 1988). The limited data collection period accounts for the small sample size. It took a long time before the children from middle/high schools in Michigan actually started self-reporting the surveys online: the school district needed time to have meetings to consider the possibility of doing this study and it took a few days to send invitation letters by mail to the children's addresses. These procedures took a major part of the study time. Moreover, other problems included a technical problem with the online survey influenced data collection period as well. Due to the low response rate of the survey and the short data collection period, participants were also recruited from WVU students who have registered in CDFS 110 class: Families Across the Lifespan. However, this step did not help much because of the short study time and the lack of a 
Personal Fable, Drug Use and Parental Monitoring in Adolescents and Young Adults

financial incentive. At last, the study ended up with only 56 participants. For a future study, if using an online survey, the researchers might need to plan more time and try to increase the monetary incentives for taking part in the study.

The second limitation for this study is also related to the demographic traits of the sample. The gender distribution was not balanced because there were much more girls than boys ( $76 \%$ in middle/high school and $96.8 \%$ in the college sample). This makes the results hard to extend to other populations that have equal gender distribution or have more male participants. Also, this limitation might account for the non-significance of the relationship between personal fable and youth drug use. Result of previous research indicated that boys tend to have higher score on the scale of invulnerability in personal fable measure (Albert et al., 2007). Future researchers might want to include more male participants and collect data from the populations that have less female students. According to a report from the American Association of University Women (2010), there were much more male students in science and engineering related classes, and future researchers might want to collect data from these classes to get more male participants.

In addition, the sample was not very risky and this might be another limitation. It can be seen from the original data that the response to lifetime and recent drug use was very low. The aim of the study was to examine drug use, so if participants never used a drug or just used a few, it would be hard to get the expected outcome. For future studies, researchers might want to collect data from some high risk populations drawn from youth service centers, psychiatric facilities, or other outreach efforts related to youth high risk taking.

This study was a cross-sectional investigation, and thus its findings cannot provide any suggestion about the direction of the relations between parental monitoring and youth drug use. It was not sure from the study whether it was the parents' knowledge that caused youth's low 
Personal Fable, Drug Use and Parental Monitoring in Adolescents and Young Adults

drug use, or the low drug use youth were the people who were willing to share their activities with parents that made their parents have more knowledge of their activities. A longitudinal study is necessary if future researchers want to know the direction of the relations between parental monitoring and youth drug use. For example, a study completed by Laird et al. (2003a) indicated a bidirectional relationship of parental monitoring and youth delinquency: low levels of parental monitoring predicted high levels of youth delinquency behavior, and the high levels of delinquency predicted low levels of parental monitoring. Laird et al.'s (2003a) study can be a hint for the bidirectional relation between parental monitoring and youth drug use because delinquency behavior was significantly related to youth drug use (Huizinga, Loeber \& Thornberry, 1993). For future researchers, it will be helpful if they have enough time to complete a longitudinal study to explain how parental monitoring and youth drug use influenced each other over time.

\section{Contributions}

Though the hypotheses in the current study were only partially supported, it gives some contributions. First, it was confirmed from the results that parental monitoring is an important factor associated with youth drug use and this finding has a practical contribution. When parents have more knowledgeable about their teens' whereabouts and activities, their children tended to show lower levels of drug use. In real life practice, parents can help prevent their children from engaging in drug use by having high levels of knowledge of their children's whereabouts and activities. Social workers and educators can help parents prevent or reduce their children's drug use by improving levels of parental monitoring. In addition, according to Kerr and Stattin's (2000) study, parental monitoring is significantly associated with their children's better social adjustment especially when they get knowledge through their children's self-disclosure. 
Personal Fable, Drug Use and Parental Monitoring in Adolescents and Young Adults

Therefore, positive and high quality parent and child relationships would be helpful because it can promote children to share their lives with parents (Kerr \& Stattin, 2000).

In addition, this study contributed to the field of youth personal fable research. It provides support to the literatures which did not find the significant relationship between youth personal fable and drug use. The study might also indicate that personal fable might not be a very significant factor that relates to youth drug use. Moreover, the current study provided a possible moderating effect of parental monitoring in the research field of youth drug use. Future researchers might consider parental monitoring as a moderator when studying youth behavior and other develpmental problems. 
Personal Fable, Drug Use and Parental Monitoring in Adolescents and Young Adults

\section{References}

Aalsma, A. C., Lapsley, D. K., \& Flannery, D. J. (2006). Personal fables, narcissism, and adolescent adjustment Psychology in the Schools, 43, 481-491.

Alberts, A., Elkind, D., \& Ginsberg, S. (2007). The personal fable and risk-taking in early adolescence. Journal of Youth and Adolescence, 36, 71-76.

American Association of University Women. (2010). Why so few? Retrieved from http://www.aauw.org/learn/research/upload/whysofew_execsummary.pdf.

Beck, K. H., Boyle, J. R., \& Boekeloo, B. O. (2003). Parental monitoring and adolescent alcohol risk in a clinic population. American Journal of Health Behavior, 27, 108-115.

Bot, S. M., Engels, R. C., Knibbe, R. A., \& Meeus, W. H. (2005). Friend's drinking behaviour and adolescent alcohol consumption: The moderating role of friendship characteristics. Addictive Behaviors, 30, 929-947.

Bahr, S. J., Hoffmann, J. P., \& Yang, X. (2005). Parental and peer influences on the risk of adolescent drug use. The Journal of Primary Prevention, 26, 529-551.

Bright, S. J., McKillop, D., \& Ryder, D. (2008). Cigarette smoking among young adults: Integrating adolescent cognitive egocentrism with the trans-theoretical model. Australian Journal of Psychology, 60, 18-25.

Brown, S.A., McGue, M., Maggs, J., Schulenberg, J., Hingson, R., Swartzwelder, S., Martin, C., Chung, T., Tapert, S. F., Sher, K., Winters, C., Lowman, C., \& Murphy, S (2009). Underage drinking: Summary of developmental processes and mechanisms: Ages 16-20. Alcohol Research and Health, 32, 41-52.

Costa, F. (2008, November). Problem behavior theory: A brief overview. [Web log post]. Retrieved from http://www.colorado.edu/ibs/jessor/pb_theory.html 
Personal Fable, Drug Use and Parental Monitoring in Adolescents and Young Adults

Centers for Disease Control and Prevention. (2004). Methodology of the youth risk behavior surveillance system. Morbidity and Mortality Weekly Report, 53 (No. RR-12).

Centers for Disease Control and Prevention. (2010). Youth risk behavior surveillance-United States, 2009. Morbidity and Mortality Weekly Report, 59 (No. SS-5).

Cohen, J. (1988). Statistical power analysis for the behavioral sciences (2nd edition). Hillsdale, NJ: Erlbaum.

Dishion, T. J., \& McMahon, R. J. (1998) Parental monitoring and the prevention of child and adolescent problem behavior: A conceptual and empirical formulation. Clinical Child and Family Psychology Review, 1, 61-75.

DiClemente, R. J., Wingood, G. M., Crosby, R., Sionean, C., Cobb, B. K., Harrington, K., Davies, S., Hook III, E. W., \& Kim, M. (2001). Parental monitoring: Association with adolescents' risk behaviors. Pediatrics, 107, 1363-1368.

Elkind, D. (1967). Egocentrism in adolescence. Child Development, 38, 1025-1034.

Elkind, D., \& Bowen, R. (1979). Imaginary audience behavior in children and adolescents. Developmental Psychology, 15, 38-44.

Elkington, K. S., Bauermeister, J. A., Brackis-Cott, E., Dolezal, C., \& Mellins, C. A. (2009). Substance use and sexual risk behaviors in perinatally human immunodeficiency virusexposed youth: Roles of caregivers, peers and HIV status. Journal of Adolescent Health, 45,133-141.

Frankenberger, K. D. (2004). Adolescent egocentrism, risk perceptions, and sensation seeking among smoking and nonsmoking youth. Journal of Adolescent Research, 19, 576-590.

Fulkerson, J. A., Pasch, E. K., Perry, C. L., \& Komro, K. (2008). Relationships between alcoholrelated informal social control, parental monitoring and adolescent problem behaviors 
Personal Fable, Drug Use and Parental Monitoring in Adolescents and Young Adults

among racially diverse urban youth. Journal of Community Health, 33,425-433.

Greene, K., Krcmar, M., Walters, L. H., Rubin, D. L., Jerold, \& Hale, L. (2000). Targeting adolescent risk-taking behaviors: The contributions of egocentrism and sensation-seeking. Journal of Adolescence, 23, 439-461.

Huizinga, D., Loeber, R., \& Thornberry, T. P. (1993). Longitudinal study of delinquency, drug use, sexual activity, and pregnancy among children and youth in three cities. Public Health Reports, 108, 90-96.

Harris, K. M., Duncan, G. J., \& Boisjoly, J. (2002). Evaluating the role of "nothing to lose" attitudes on risky behavior in adolescence. Social Forces, 80, 1005-1039.

Henry, K. L., Oetting, E. R., \& Slater, M. D. (2009). The role of attachment to family, school, and peers in adolescents' use of alcohol: A longitudinal study of within- person and between-persons effects. Journal of Counseling Psychology, 56, 564-572.

Jessor, R., Graves, T. D., Hanson, R. C., \& Jessor, S. L. (1968). Society, personality, and deviant behavior: A study of a tri-ethnic community. New York: Holt, Rinehart \& Winston.

Jessor, R., \& Jessor, S. L. (1977). Problem behavior and psychosocial development: A longitudinal study of youth. New York: Academic Press.

Jessor, R. (1991). Risk behavior in adolescence: A psychosocial framework for understanding and Action. Journal of Adolescent Health, 12, 597-605.

Kerr, M., \& Stattin, H. (2000). What parents know, how they know it, and several forms of adolescent adjustment: Further support for a reinterpretation of monitoring. Developmental Psychology, 36, 366-380.

Kristjansson, A. L., James, J. E., Allegrante, J. P., Sigfusdottir, I. D., \& Helgason, A. R. (2010). Adolescent substance use, parental monitoring, and leisure-time activities: 12-year 
Personal Fable, Drug Use and Parental Monitoring in Adolescents and Young Adults

outcomes of primary prevention in Iceland. Preventive Medicine, 51, 168-171.

Lapsley, D. K. (1993). Toward an integrated theory of adolescent ego development: The "new look" at adolescent egocentrism. American Journal of Orthopsychiatry, 63, 562-571.

Li, X., Feigelman S., \& Stanton, B. (2000). Perceived parental monitoring and health risk behaviors among urban low-income African-American children and adolescents. Journal of Adolescent Health, 27, 43-48.

Laird, R. D., Pettit, G. S., Bates, J. E., \& Dodge, K. A. (2003a). Parents' monitoring-relevant knowledge and adolescents' delinquent behavior: Evidence of correlated developmental changes and reciprocal influence. Child Development, 74, 752-768.

Laird, R. D., Pettit, G. S., Dodge, K. A., \& Bates, J. E. (2003b). Change in parents' monitoring knowledge: Links with parenting, relationship quality, adolescent beliefs, and antisocial behavior. Social Development, 12, 401-419.

Lee, A., \& Tsang, C. K. K. (2004). Youth risk behaviour in a Chinese population: A territory-wide youth risk behavioural surveillance in Hong Kong. Public Health, 118, 8895.

Loftin, L. (2009, March 30). Issue of the day: Drug policies have failed, states Clinton [Project American]. Retrieved from http://www.project.org/blog/?p=1194.

Morris, A. S., Silk, J. S., Steinberg, L., Myers, S. S., \& Robinson, L. R. (2007). The role of the family context in the development of emotion regulation. Social Development, 16, 361-388.

Moilanen, K. L., Shaw, D. S., Criss, M., \& Dishion, T. J. (2009). Growth and predictors of parental knowledge of youth behavior during early adolescence. Journal of Early Adolescence, 29, 800-825. 
Personal Fable, Drug Use and Parental Monitoring in Adolescents and Young Adults

McKenzie, M., Olsson, C. A., Jorm, A. F., Romaniuk, H. \& Patton, G. C. (2010). Association of adolescent symptoms of depression and anxiety with daily smoking and nicotine dependence in young adulthood: findings from a 10-year longitudinal study. Addiction, 105, 1652-1659.

Newcomb, M. D., \& Bentler, P. M. (1988). Impact of adolescent drug use and social support on problems of young adults: A longitudinal study. Journal of Abnormal Psychology, 97, 6475.

Omori, M., \& Ingersoll, G. M. (2005). Health-endangering behaviors among Japanese college students: a test of psychosocial model of risk-taking behaviours. Journal of Adolescence, $28,17-33$.

Office of National Drug Control Policy. ( n.d.). Marijuana myths \& facts: The truth behind 10 popular misperceptions. Retrieved November 3, 2011, from https://www.ncjrs.gov/ondcppubs/publications/pdf/marijuana_myths_facts.pdf

Percy, A. (2008). Moderate adolescent drug use and the development of substance use selfRegulation. International Journal of Behavioral Development, 5, 451-458.

Pokhrel, P., Unger, J. B., Wagner, K. D., Ritt-Olson, A., \& Sussman, S. (2008). Effects of parental monitoring, parent-child communication, and parents' expectation of the child's acculturation on the substance use behaviors of urban, Hispanic adolescents. Journal of Ethnicity in Substance Abuse, 7, 200-213.

Serovich, J. M., \& Greene, K. (1997). Predictors of adolescent sexual risk taking behaviors which put them at risk for contracting HIV. Journal of Youth and Adolescence, 26, 429444.

Stattin, H., \& Kerr, M. (2000). Parental monitoring: A reinterpretation. Child Development, 71, 
Personal Fable, Drug Use and Parental Monitoring in Adolescents and Young Adults

1072-1085.

Shillington, A. M., Lehman, S., Clapp, J., Hovell, M. F., Sipan, C., \& Blumberg, E. J. (2005). Parental monitoring: Can it continue to be protective among high-risk adolescents? Journal of Child \& Adolescent Substance Abuse, 15, 1-15.

Substance Abuse and Mental Health Services Administration. (2010). Results from the 2009 National Survey on Drug Use and Health: Volume I. Summary of National Findings (Office of Applied Studies, NSDUH Series H-38A, HHS Publication No. SMA 10-4586 Findings). Rockville, MD.

Townsend, L., Flisher, A.J., \& King, G. (2007). A systematic review of the relationship between high school dropout and substance use. Clinical Child and Family Psychology, 10, 295317.

Vartanian, L. R. (2000). Revisiting the imaginary audience and personal fable constructs of adolescent egocentrism: A conceptual review. Adolescence, 35, 639-657.

Webb, J. A., Bray, J. H., Getz, J. G., \& Adams, G. (2002). Gender, perceived parental monitoring, and behavioral adjustment: Influences on adolescent alcohol use. American Journal of Orthopsychiatry, 72, 392-400.

Wood, M. D., Read, J. P., Mitchell, R. E., \& Brand, N. H. (2004). Do parents still matter? Parent and peer influences on alcohol involvement among recent high school graduates. Psychology of Addictive Behaviors, 18, 19-30.

Yu, S., Rebecca, C., Yang, H., Li, X., Bonita, S., Lynette, D., Sonja, L., Lesley, C., \& Carole, H. (2006). Youth and parental perceptions of parental monitoring and parent-adolescent communication, youth depression, and youth risk behaviors. Social Behavior and Personality, 34, 1297-1310. 
Personal Fable, Drug Use and Parental Monitoring in Adolescents and Young Adults

Yucel, M., Zalesky, A., Takagi, M. J., Bora, E., Fornito, A., Ditchfield, M., Egan, G. F., Pantelis, C., \& Lubman, D. I. (2010). White-matter abnormalities in adolescents with long-term inhalant and cannabis use: A diffusion magnetic resonance imaging study. Journal of Psychiatry and Neuroscience, 35, 409-412. 
Personal Fable, Drug Use and Parental Monitoring in Adolescents and Young Adults

APPENDIX A

DEMOGRAPHIC INFORMATION

What is your sex? Female Male

How old are you in years?

What is your birthdate?

What is your current grade in school?

$7^{\text {th }}$
$-8^{\text {th }}$
$-9^{\text {th }}$
$-10^{\text {th }}$
$-11^{\text {th }}$

Other (please specify

To what racial group do you belong? Select all that apply.

Native American / Indian

Black / African American

White / Caucasian

_Asian / Asian American

Pacific Islander

Other (please specify

Do you consider yourself to be Hispanic or Latino?

- Yes

No

Don't know

_Don't wish to answer

To your knowledge, what is your family's yearly income?

_Under $\$ 20,000$

$\$ 20,000-\$ 39,999$

$\$ 40,000$ - \$59,999

$\$ 60,000$ - $\$ 79,999$

$\$ 80,000$ - $\$ 99,999$

$\$ 100,000+$

Don't know

Don't wish to answer 
Personal Fable, Drug Use and Parental Monitoring in Adolescents and Young Adults

With whom do you live? Select all that apply.

Both biological parents (mom \& dad)

One biological parent: mom

_ One biological parent: dad

_Mom \& stepdad

Dad \& stepmom

Mom \& grandparent(s)

Dad \& grandparent(s)

Grandparent(s)

_Brother(s) \&/or sister(s)

Do not wish to answer

Somebody else (please specify) 
Personal Fable, Drug Use and Parental Monitoring in Adolescents and Young Adults

APPENDIX B

DEMOGRAPHIC INFORMATION

What is your sex? Female___ Male

How old are you in years?

What is your birthdate?

What is your current grade in school?

_First ("Freshman")

_Second ("Sophomore")

_Third ("Junior")

Fourth ("Senior")

Do not wish to answer

Other (please explain)

To what racial group do you belong? Select all that apply.

Native American / Indian

Black / African American

White / Caucasian

__Asian / Asian American

Pacific Islander

Other (please specify

Do you consider yourself to be Hispanic or Latino?

- Yes

_No

Don't know

_Don't wish to answer

To your knowledge, what is your family's yearly income?

_Under $\$ 20,000$

$\$ 20,000$ - $\$ 39,999$

$\$ 40,000$ - \$59,999

$\$ 60,000$ - $\$ 79,999$

$\$ 80,000$ - $\$ 99,999$

$\$ 100,000+$

Don't know

Don't wish to answer 
Personal Fable, Drug Use and Parental Monitoring in Adolescents and Young Adults

With whom do you live? Select all that apply.

Both biological parents (mom \& dad)

One biological parent: mom

_One biological parent: dad

_.Mom \& stepdad

_Dad \& stepmom

Mom \& grandparent(s)

Dad \& grandparent(s)

-Grandparent(s)

Brother(s) \&/or sister(s)

Do not wish to answer

Somebody else (please specify) 
Personal Fable, Drug Use and Parental Monitoring in Adolescents and Young Adults

\section{APPENDIX C}

\section{PERSONAL FABLE SCALE}

Please read each statement below and indicate how true each statement is of you.

Remember, there are no right or wrong answers, and you are free to skip any questions you do not wish to answer.

1 -Never true for me

2--- Rarely true for me

3---Sometimes true for me

4---Often true for me

5---Always true for me

1. Some kids believe that they don't need to put on their seatbelt every time they get in a car.

2. Some kids think that wearing a helmet while skateboarding, biking, or rollerblading is unnecessary because nothing is going to happen to them.

3. When my parents or friends tell me that they know how I feel, I don't believe that they really do.

4. I know I get away with a lot of stuff other kids get in trouble for.

5. When teams are picked in gym or at recess, I know I will never be the one picked last.

6. Although I know that many other people may never realize their goals and ambitions I am sure that I will.

7. Some kids don't worry about getting injured when they play sports.

8. When I realize I have said or done something really hurtful to a good friend it seems to me that no one else has ever done anything quite so bad.

9. I don't worry about what I eat because I know I won't get fat.

10. Even though other kids, besides me, got A's on their papers, I feel that the teacher liked mine the best.

11. Sometimes when I see a good-looking girl/boy, I think that they are looking at me in a very admiring way.

12. Some kids believe that even if they try drugs they will never get hooked on them. 
Personal Fable, Drug Use and Parental Monitoring in Adolescents and Young Adults

\section{APPENDIX D}

\section{PARENTAL MONITORING SCALE}

Below are questions about whether your parents have knowledge of the things you do and with whom you are hanging out. Please indicate how much you agree or disagree with each of the following statements.

Remember, this isn't a test, and there are no right or wrong answers. You are free to skip any questions you do not wish to answer.

1.----Strongly disagree

2.----Disagree

3.----Neither agree nor disagree

4.----Agree

5.----Strongly agree

1. Do your parents know who you have as friends during your free time?

2. Do your parents know how you do in different subjects at school?

3. Do your parents usually know what type of homework you have?

4. Do your parents know what you do during your free time?

5. Do your parents usually know when you have an exam or paper due at school?

6. Do your parents normally know where you go and what you do after school?

7. Do your parents know where you go when you are out with friends at night?

8. In the last month, have your parents ever had no idea of where you were at night?

9. Do your parents know what you spend your money on? 
Personal Fable, Drug Use and Parental Monitoring in Adolescents and Young Adults

\section{APPENDIX E}

\section{SUBSTANCE USE}

This next part of the study is about health behavior. It has been developed so you can tell us what you do that may affect your health.

As in all other parts of the survey, the answers you give to these questions will be kept private. No one will know what you tell us. Please answer the questions based on what you really do. You can skip any questions you do not wish to answer.

In your lifetime, have you ever tried or used the following substances?

1. Cigarettes, even just a puff or two?

2. Chewing tobacco, snuff, or dip (e.g., Skoal, Copenhagen)?

3. Cigars, cigarillos, or little cigars?

$\begin{array}{rr}\text { Yes } & \text { No } \\ \text { Yes } & \text { No } \\ \text { Yes } & \text { No } \\ \text { Yes } & \text { No } \\ \text { Yes } & \text { No }\end{array}$

5. Marijuana (i.e., pot, grass, weed)?

6. Sniffed glue, breathed the contents of aerosol spray cans, or inhaled any paints or sprays to get high? Yes No

7. Any form of cocaine, including powder, crack or freebase?

8. Heroin (i.e., smack, junk, or China White)?

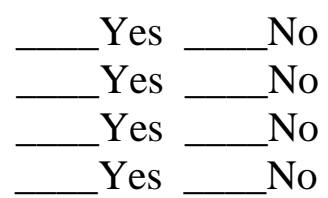

9. Methamphetamines (e.g.,
10. Ecstasy (e.g., MDMA)? Yes

11. Any hallucinogenic drugs (e.g., LSD, acid, PCP, angel dust, or mushrooms)? Yes _ No

12. Any steroid pills or shots without a doctor's prescription? Yes No

13. Any prescription drug without a doctor's prescription (e.g., OxyContin, Percoset, Vicodin, codeine, Adderall, Ritalin, or Xanax)? Yes _ No 
Personal Fable, Drug Use and Parental Monitoring in Adolescents and Young Adults

1. 0 days

\section{During the past 30 days, on how many days did you...}

2. 1-2 days

3. 3-5 days

4. 6-9 days

5. 10-19 days

6. 20-29 days

7. All 30 days

8. Do not wish to answer

1. Cigarettes, even just a puff or two?

2. Chewing tobacco, snuff, or dip (e.g., Skoal, Copenhagen)?

3. Cigars, cigarillos, or little cigars?

4. Alcohol, more than just a sip or two (e.g., beer, wine, or liquor)?

5. Marijuana (i.e., pot, grass, weed)?

6. Sniffed glue, breathed the contents of aerosol spray cans, or inhaled any paints or sprays to get high?

7. Any form of cocaine, including powder, crack or freebase?

8. Heroin (i.e., smack, junk, or China White)?

9. Methamphetamines (e.g., meth, speed, crystal, crank, or ice)?

10. Ecstasy (e.g., MDMA)?

11. Any hallucinogenic drugs (e.g., LSD, acid, PCP, angel dust, or mushrooms)?

12. Any steroid pills or shots without a doctor's prescription?

13. Any prescription drug without a doctor's prescription (e.g., OxyContin, Percoset, Vicodin, codeine, Adderall, Ritalin, or Xanax)? 
Personal Fable, Drug Use and Parental Monitoring in Adolescents and Young Adults

Table 1

Study Variable Descriptive Statistics by Subsample

\begin{tabular}{|c|c|c|}
\hline \multirow[t]{3}{*}{ Variables } & High School and & College Sample \\
\hline & \multicolumn{2}{|c|}{ Middle School Sample } \\
\hline & $\mathrm{M}(\mathrm{SD}) / \%$ & $\mathrm{M}(\mathrm{SD}) / \%$ \\
\hline$N$ & 25 & 31 \\
\hline$\%$ Female & $76.00 \%$ & $96.80 \%$ \\
\hline Age in Years & $14.68(1.64)$ & $19.03(1.13)$ \\
\hline$\%$ Caucasian & $96.00 \%$ & $96.80 \%$ \\
\hline \multirow[t]{5}{*}{ Grade in School } & $24.00 \% 8^{\text {th }}$ & $45.20 \%$ Freshman \\
\hline & $16.00 \% 9^{\text {th }}$ & $22.60 \%$ Sophomore \\
\hline & $24.00 \% 10^{\text {th }}$ & $22.60 \%$ Junior \\
\hline & $32.00 \% 11^{\text {th }}$ & $9.70 \%$ Senior \\
\hline & $4.00 \% 12^{\text {th }}$ & \\
\hline LVBBP & $76.00 \%$ & $61.00 \%$ \\
\hline \multicolumn{3}{|l|}{ CCGS } \\
\hline Mother & $64.00 \%$ & $74.20 \%$ \\
\hline Father & $40.00 \%$ & $64.50 \%$ \\
\hline Personal Fable & $31.35(6.38)$ & $31.68(6.13)$ \\
\hline Parental Monitoring & $37.50(3.60)$ & $32.30(8.20)$ \\
\hline Lifetime Drug Use & $0.20(0.41)$ & $2.47(1.66)$ \\
\hline Recent Drug Use & $3.25(0.91)$ & $5.87(2.78)$ \\
\hline
\end{tabular}

Note . CCGS = Completed college/graduate school; LVBBP = Live with both biological parents. Score ranges from 12 to 60 for the personal fable scale, 9 to 45 for the parental monitoring scale, 
Personal Fable, Drug Use and Parental Monitoring in Adolescents and Young Adults

0 to 13 for the lifetime drug use measure, and 13 to 91 for the recent drug use scale. In lifetime drug use scale, only one student reported the experience of drug usage. 
Personal Fable, Drug Use and Parental Monitoring in Adolescents and Young Adults

Table 2

Study Variable Descriptive Statistics \& Correlations

$\begin{array}{lllll}M & S D & 1 & 2 & 3\end{array}$

1 Personal Fable $\quad 31.55 \quad 6.17$

2 Parental Monitoring $\quad 34.25 \quad 7.26 \quad-.33^{*}$

3 Lifetime Drug Use $\quad \begin{array}{llll}\text { (.56 } & 1.72 & .15 & -.49^{* *}\end{array}$

\begin{tabular}{|c|c|}
\hline 4 Recent Drug Use & 4.82 \\
\hline
\end{tabular}

Note. ${ }^{*} p<.05, * * p<.01$ (2-tailed). 
Personal Fable, Drug Use and Parental Monitoring in Adolescents and Young Adults Table 3

Results of Hierarchical Regression Analysis Predicting Youth Lifetime Drug Use

\begin{tabular}{|c|c|c|c|}
\hline & & Step & \\
\hline & 1 & 2 & 3 \\
\hline & $\beta$ & $\beta$ & $\beta$ \\
\hline Group & $.62 * * *$ & $.51 * * *$ & $.52 * * *$ \\
\hline Personal Fable & & .01 & .03 \\
\hline Parental Monitoring & & $-.30 *$ & $-.32 *$ \\
\hline Personal Fable x Parental Monitoring & & & .08 \\
\hline$R^{2}$ & .38 & .47 & .47 \\
\hline
\end{tabular}


Personal Fable, Drug Use and Parental Monitoring in Adolescents and Young Adults

Table 4

Results of Hierarchical Regression Analysis Predicting Recent Drug Use

\begin{tabular}{|c|c|c|c|}
\hline & & Step & \\
\hline & 1 & 2 & 3 \\
\hline & $\beta$ & $\beta$ & $\beta$ \\
\hline Group & $.47 * * *$ & $.38 * *$ & $.40 * * *$ \\
\hline Personal Fable & & -.09 & -.04 \\
\hline Parental Monitoring & & -.28 & $-.35 *$ \\
\hline Personal Fable x Parental Monitoring & & & .25 \\
\hline $\mathrm{R} 2$ & .22 & .28 & .33 \\
\hline
\end{tabular}

Note. All weights are standardized. $* p<.05 ; * * p<.01 ; * * * p<.001$. 
Personal Fable, Drug Use and Parental Monitoring in Adolescents and Young Adults

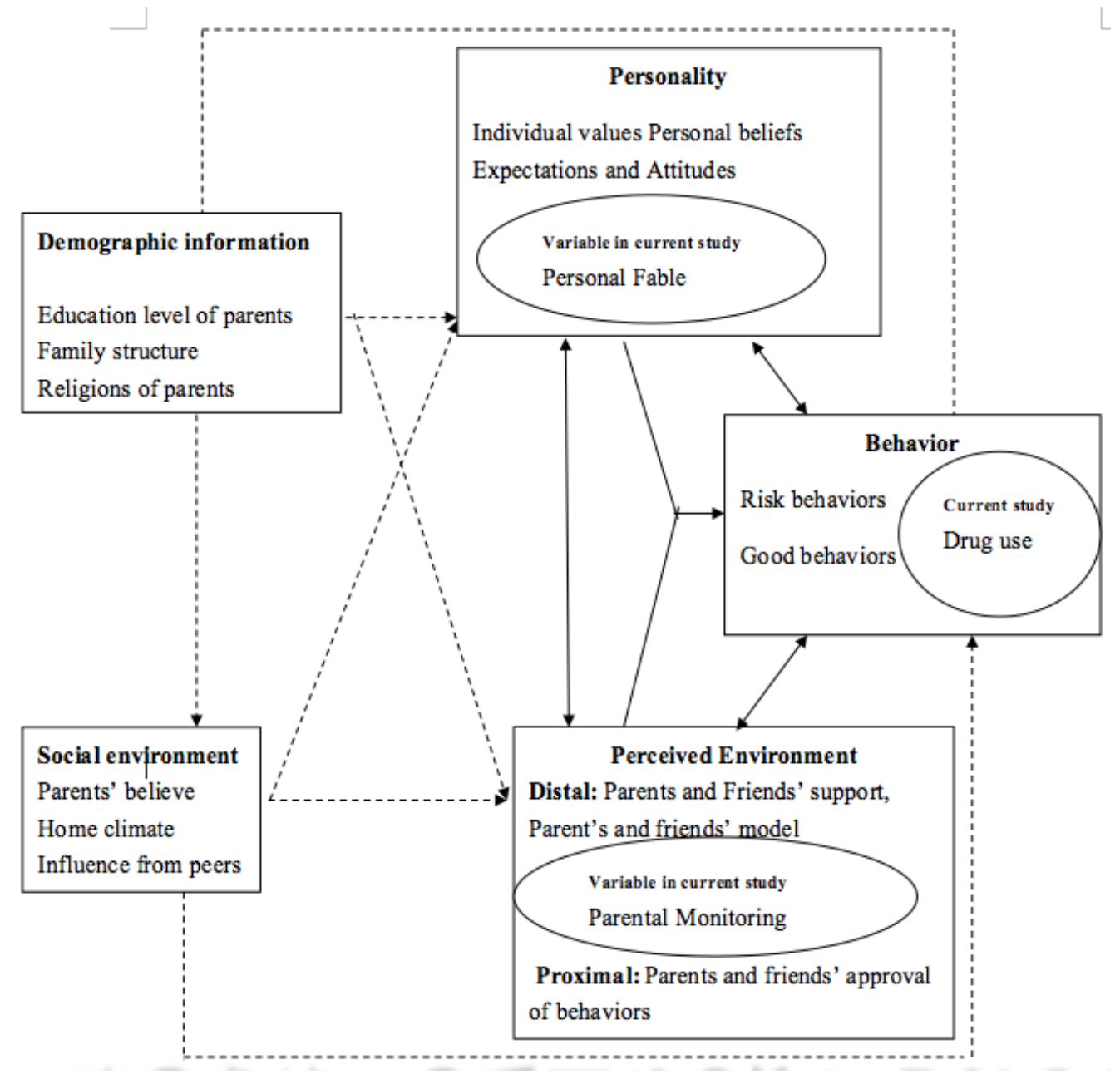

Figure 1: Problem Behavior Theory. This figure illustrated different systems in problem behavior theories and variables in the current study. 
Personal Fable, Drug Use and Parental Monitoring in Adolescents and Young Adults

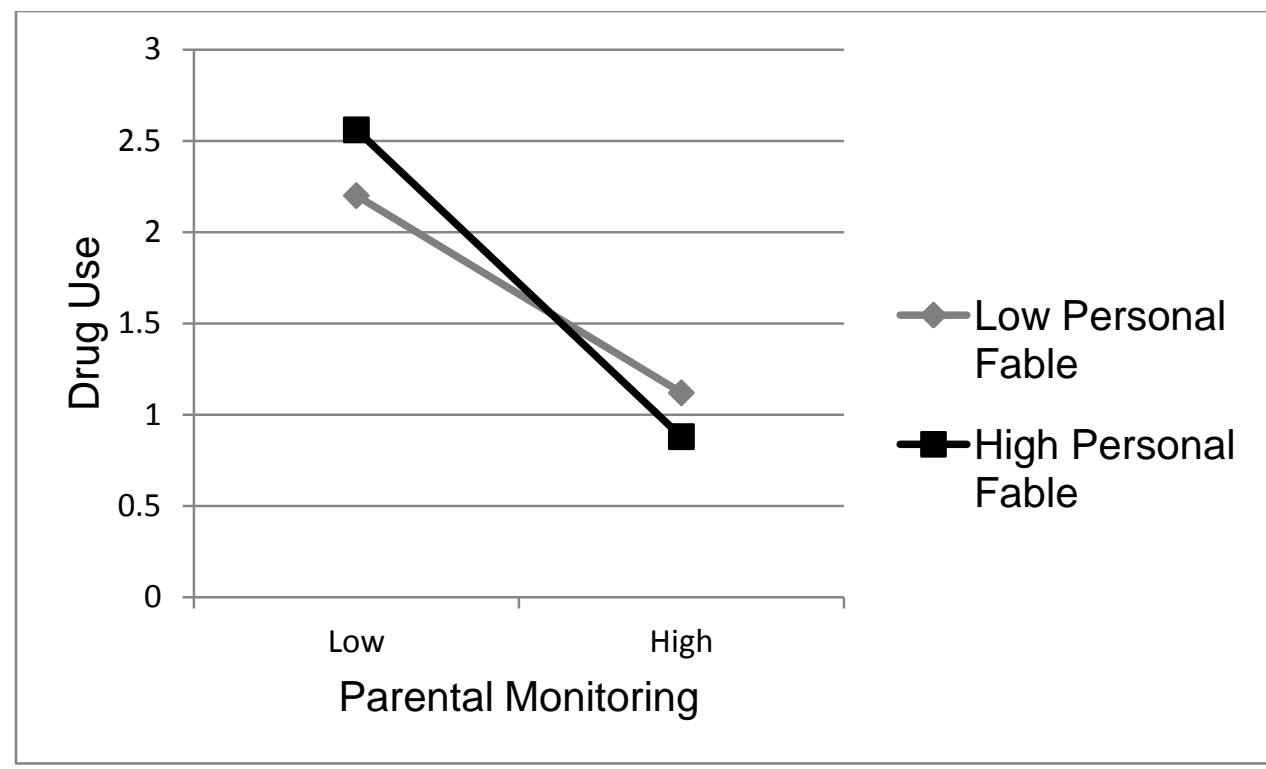

Figure 2: Interaction effect of parental monitoring and the personal fable on youths' lifetime drug use.

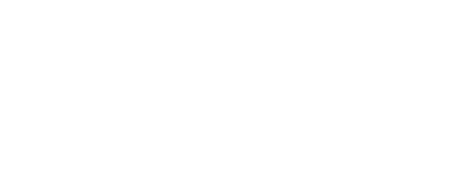

